\title{
A possible brachiosaurid (Dinosauria, Sauropoda) from the mid-Cretaceous of northeastern China
}

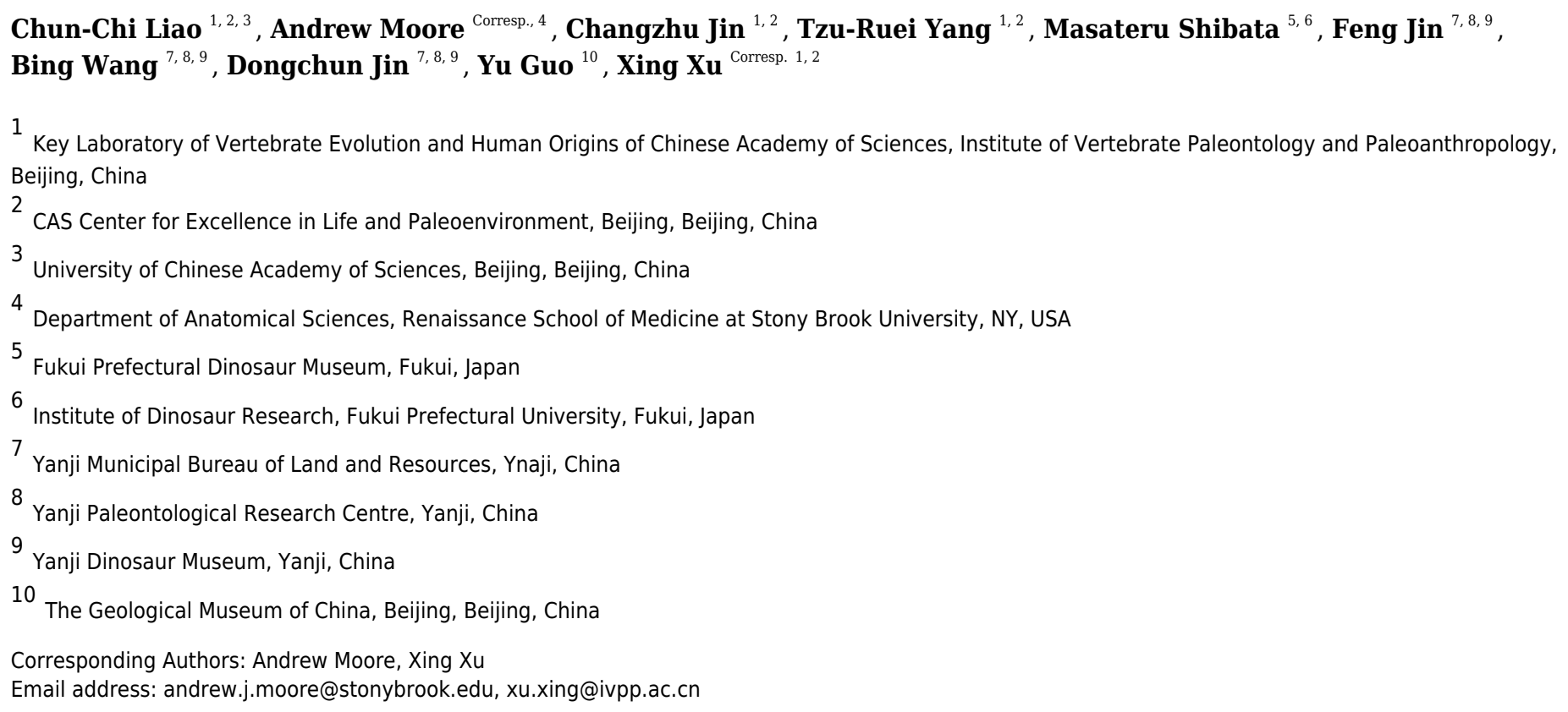

Brachiosauridae is a lineage of titanosauriform sauropods that includes some of the most iconic non-avian dinosaurs. Undisputed brachiosaurid fossils are known from the Late Jurassic through the Early Cretaceous of North America, Africa, and Europe, but proposed occurrences outside this range have proven controversial. Despite occasional suggestions that brachiosaurids dispersed into Asia, to date no fossils have provided convincing evidence for a pan-Laurasian distribution for the clade, and the failure to discover brachiosaurid fossils in the well-sampled sauropod-bearing horizons of the Early Cretaceous of Asia has been taken to evidence their genuine absence from the continent. Here we report on an isolated sauropod maxilla from the middle Cretaceous (Albian-Cenomanian) Longjing Formation of the Yanji basin of northeast China. Although the specimen preserves limited morphological information, it exhibits axially twisted dentition, a shared derived trait otherwise known only in brachiosaurids. Referral of the specimen to the Brachiosauridae receives support from phylogenetic analysis under both equal and implied weights parsimony, providing the most convincing evidence to date that brachiosaurids dispersed into Asia at some point in their evolutionary history. Inclusion in our phylogenetic analyses of an isolated sauropod dentary from the same site, for which an association with the maxilla is possible but uncertain, does not substantively alter these results. We consider several paleobiogeographic scenarios that could account for the 
occurrence of a middle Cretaceous Asian brachiosaurid, including dispersal from either North America or Europe during the Early Cretaceous. The identification of a brachiosaurid in the Longshan fauna, and the paleobiogeographic histories that could account for its presence there, are hypotheses that can be tested with continued study and excavation of fossils from the Longjing Formation. 
2 A possible brachiosaurid (Dinosauria, Sauropoda) 3 from the mid-Cretaceous of northeastern China

4

5

Liao Chun-Chi ${ }^{1,2,3}$, Andrew Moore ${ }^{4}$, Jin Changzhu ${ }^{1,2}$, Yang Tzu-Ruei ${ }^{1,2}$, Shibata Masateru ${ }^{5,6}$, Jin Feng ${ }^{7,8,9}$, Wang Bing ${ }^{7,8,9}$, Jin Dongchun ${ }^{7,8,9}$, Guo $\mathrm{Yu}^{10}$, Xu Xing ${ }^{1,2}$

${ }^{1}$ Key Laboratory of Vertebrate Evolution and Human Origins of Chinese Academy of Sciences, Institute of Vertebrate Paleontology and Paleoanthropology, Chinese Academy of Sciences, Beijing, 100044, China

${ }^{2}$ CAS Center for Excellence in Life and Paleoenvironment, Beijing, China

${ }^{3}$ University of Chinese Academy of Sciences, Beijing, 100049, China

${ }^{4}$ Department of Anatomical Sciences, Renaissance School of Medicine at Stony Brook University, Stony Brook, NY, 11794, USA

${ }^{5}$ Institute of Dinosaur Research, Fukui Prefectural University, Fukui 910-1195, Japan

${ }^{6}$ Fukui Prefectural Dinosaur Museum, Fukui 911-8601, Japan

${ }^{7}$ Yanji Municipal Bureau of Land and Resources, Yanji 133001, China.

${ }^{8}$ Yanji Paleontological Research Centre, Yanji 133001, China.

${ }^{9}$ Yanji Dinosaur Museum, Yanji 133001, China.

${ }^{10}$ The Geological Museum of China, Beijing 100034, China.

Corresponding Authors:

Xu Xing ${ }^{1,2}$

142 Xizhimenwai Str., Beijing, 100044, China

Email address: xu.xing@ivpp.ac.cn

Andrew Moore ${ }^{4}$

101 Nicolls Road, Health Sciences Center, Level 4, Stony Brook, NY 11794, USA

Email address: andrew.j.moore@stonybrook.edu

\section{Abstract}

Brachiosauridae is a lineage of titanosauriform sauropods that includes some of the most iconic non-avian dinosaurs. Undisputed brachiosaurid fossils are known from the Late Jurassic through the Early Cretaceous of North America, Africa, and Europe, but proposed occurrences outside this range have proven controversial. Despite occasional suggestions that brachiosaurids dispersed into Asia, to date no fossils have provided convincing evidence for a pan-Laurasian distribution for the clade, and the failure to discover brachiosaurid fossils in the well-sampled sauropod-bearing horizons of the Early Cretaceous of Asia has been taken to evidence their genuine absence from the continent. Here we report on an isolated sauropod maxilla from the middle Cretaceous (Albian-Cenomanian) Longjing Formation of the Yanji basin of northeast China. Although the specimen preserves limited morphological information, it exhibits axially twisted dentition, a shared derived trait otherwise known only in brachiosaurids. Referral of the specimen to the Brachiosauridae receives support from phylogenetic analysis under both equal and implied weights parsimony, providing the most convincing evidence to date that 
46 brachiosaurids dispersed into Asia at some point in their evolutionary history. Inclusion in our
47 phylogenetic analyses of an isolated sauropod dentary from the same site, for which an

47

48

49

50

51

52

53

54

55

56

57

58

59

60

61

62

63

64

65

66

67

68

69

70

71

72

73

74

75

76

77

78

79

80

81

82

83

84

85

86

87

88

89

90

91 association with the maxilla is possible but uncertain, does not substantively alter these results. We consider several paleobiogeographic scenarios that could account for the occurrence of a middle Cretaceous Asian brachiosaurid, including dispersal from either North America or Europe during the Early Cretaceous. The identification of a brachiosaurid in the Longshan fauna, and the paleobiogeographic histories that could account for its presence there, are hypotheses that can be tested with continued study and excavation of fossils from the Longjing Formation.

\section{Introduction}

Brachiosauridae is a clade of titanosauriform sauropods and one of the most iconic groups of non-avian dinosaurs, with well-known exemplars that include the Late Jurassic taxa Giraffatitan and Brachiosaurus. Although the in-group membership and inter-relationships of the clade remain a subject of continued debate (e.g., D’Emic, 2012; Mannion et al., 2013, 2017; Carballido et al., 2015, 2020; D'Emic et al., 2016; Royo-Torres et al., 2017), Brachiosauridae and slightly less inclusive subclades are readily diagnosed by a suite of characteristics from across the skeleton that are rare or absent among other lineages of sauropods (Wilson \& Sereno, 1998; D'Emic, 2012; Mannion et al., 2013 2017). These include bauplan-defining traits, such as an elongate humerus that nearly equals or exceeds the length of the femur, as well as more subtle features of the skull and post-cranial skeleton, including axially twisted maxillary dentition, a small contribution of the ischium to the acetabulum, and a relatively broad proximal end of metacarpal III.

The oldest known brachiosaurid is from the Oxfordian of France (Lapparent, 1943; Mannion et al., 2017), and available body fossil evidence indicates that the lineage survived until the early Late Cretaceous, with the youngest brachiosaurids known from around the Albian/Cenomanian boundary (Chure et al., 2010; D'Emic et al., 2016). During the Late Jurassic, brachiosaurids enjoyed a cosmopolitan distribution that included Africa (Janensch, 1914), North America (Riggs, 1903), Europe (Antunes \& Mateus, 2003; Mannion et al. 2013, 2017; Mocho et al., 2016) and possibly South America (Rauhut, 2006; but see Mannion et al., 2013). Until recently, regional extinction of brachiosaurids across much of their Late Jurassic range was thought to have limited the group to North America during the Early Cretaceous (D'Emic, 2012; Mannion et al. 2013). However, the discovery of the brachiosaurid Soriatitan from the late Hauterivian-early Barremian of Spain (Royo-Torres et al., 2017), isolated vertebrae from the Berriasian-Hauterivian Kirkland Formation of South Africa referrable to Brachiosauridae (McPhee et al., 2016), isolated teeth showing axial twisting from the Early Cretaceous of Lebanon (Buffetaut et al., 2006; Mannion et al., 2013), and, potentially, the disputed brachiosaurid Padillasaurus from the Barremian of Colombia (Carballido et al., 2015, 2020; Mannion et al., 2017) reject the hypothesis that brachiosaurids suffered a major range contraction across the Jurassic/Cretaceous boundary. Although fossil evidence has occasionally been advanced to suggest that brachiosaurids dispersed into Asia (Lim et al., 2001; You \& Li, 2009), the evidence underlying these claims has not held up to subsequent scrutiny (Barrett et al., 2002; Ksepka \& Norell, 2010; Mannion, 2011; see Discussion). The failure to recover compelling evidence of brachiosaurids in the well-sampled sauropod-bearing horizons of the Early Cretaceous of Asia has been interpreted as a genuine indication that their Laurasian range was limited to Europe and North America (Ksepka \& Norell, 2010; D’Emic, 2012; Mannion et al., 2013).

Peer] reviewing PDF | (2021:04:60622:1:0:NEW 7 Jul 2021) 
92 In our 2016 expeditions to the Longshan Beds of the Longjing Formation in Yanji City, Jilin

93 Province, northeastern China, we discovered a mid-Cretaceous (Albian-Cenomanian) terrestrial

94 fauna that has produced more than two hundred vertebrate fossils, including dinosaurians,

95 crocodyliforms, and testudines. Sauropod dinosaurs represent the dominant group in the

96 Longshan fauna (Jin et al., 2018) with more than 60 bones belonging to at least 14 individuals

97 discovered so far. Most of these specimens were collected in the course of controlled excavations

98 by our team, but some additional fossils were retrieved from heaps of excavated sediment from a

99 nearby construction site. Among the latter are numerous dinosaurian and other unidentified teeth,

100 a relatively complete crocodylian specimen, and an isolated sauropod maxilla and partial

101 dentary. Because they were collected by our team after their exhumation, it is unknown whether

102 the maxilla and dentary were preserved in association, and we conservatively consider them to

103 belong to separate individuals. Whereas other sauropod fossils excavated from the Longshan

104 beds either lack brachiosaurid synapomorphies (e.g., middle dorsal vertebrae with long,

105 dorsoventrally short transverse processes; ratio of anteroposterior length of proximal plate of

106 ischium to ischial proximodistal length $\leqq 0.25$ ) or bear features not known to occur in

107 brachiosaurids (e.g. subcylindrical tooth crowns; bifurcated anterior dorsal neural spines), the

108 isolated sauropod maxilla exhibits a mosaic combination of morphological features that suggest

109 brachiosaurid affinities. Here we describe the morphology of the isolated maxilla, report on

110 phylogenetic analyses that support its referral to Brachiosauridae, and discuss

111 paleobiogeographic scenarios that could account for the occurrence of a middle Cretaceous

112 Asian brachiosaurid. We also describe the isolated sauropod dentary from the same site, and

113 discuss the effects that treating this specimen as belonging to the same individual as the isolated

114 maxilla has on our results.

115

\title{
116 Materials \& Methods
}

\section{Institutional abbreviations}

118 CM, Carnegie Museum of Natural History, Pittsburg, USA; IVPP, Institute of Vertebrate

119 Paleontology and Paleoanthropology, Beijing, China; MB.R., Museum für Naturkunde, Berlin,

120 Germany; MDT-PV, Museo Desiderio Torres-Paleovertebrados, Sarmiento, Chubut, Argentina;

121 PMU, Palaeontological Museum, Uppsala, Sweden; USNM, National Museum of Natural

122 History, Smithsonian Institution, Washington, DC, USA. YJDM, Yanji Dinosaur Museum, Jilin,

123 China.

124

125

126

127

128

129

130

131

132

133

134

135

136

137

\author{
Systematic Paleontology \\ Dinosauria Owen, 1842 \\ Saurischia Seeley, 1887 \\ Sauropoda Marsh, 1878 \\ Brachiosauridae Riggs, 1904 \\ Brachiosauridae indet.
}

Material. YJDM 00008, a partial left maxilla with dentition in situ.

Locality and horizon. The Longshan locality $\left(42^{\circ} 52^{\prime} 10.0^{\prime \prime} \mathrm{N}, 129^{\circ} 29^{\prime} 28.1^{\prime \prime} \mathrm{E}\right)$ is located south of Yanji City, Jilin Province (Fig. 1). The beds at the Longshan locality are part of the lower portion of the Longjing Formation, which conformably overlies the Dalazi Formation (Jin et al., 2018; Zhong et al., 2021). Paleontological and radiochronological data indicate an Albian to 
138 Cenomanian age for the Longjing Formation (Jin et al., 2018). The fossil-bearing site from

139 which YJDM 00008 was recovered lies a short distance above a tuff layer from near base of the

140 Longjing Formation that has recently been dated to $101.039 \pm 0.061 \mathrm{Ma}$ (Zhang et al., 2018;

141 Zhong et al., 2021); this finding is consistent with other U-Pb radiochronological dating of the

142 uppermost part of the Dalazi Formation to $105.14 \pm 0.37$ (Zhong et al., 2021). Thus, the

143 Longshan section likely includes the Albian/Cenomanian boundary, and most of the Longjing

144 Formation can be considered Cenomanian in age (Zhong et al., 2021).

145

146

147

148

149

150

151

152

153

154

155

156

157

158

159

160

161

162

163

164

165

166

\section{Description and comparisons}

Description of YJDM 00008 was facilitated by X-ray computed tomography scanning of the specimen. The scan was performed using the $450 \mathrm{kV}$ industrial X-ray computed tomography scanner (developed by the Institute of High Energy Physics, Chinese Academy of Sciences (CAS)) at the Key Laboratory of Vertebrate Evolution and Human Origins, CAS. The specimen was scanned with a beam energy of $430 \mathrm{kV}$ and a flux of $1.5 \mathrm{~mA}$ at a resolution of $160 \mathrm{um}$ per pixel using a $360^{\circ}$ rotation with a step size of $0.25^{\circ}$. A total of 1,440 projections were reconstructed in a 2,048 x 2,048 matrix of 2,048 slices using a two-dimensional reconstruction software developed by the Institute of High Energy Physics, CAS (Wang et al., 2019). Data were output in the raw file format and imported into Mimics v.19.0 (Materialise, 2015, Leuven, Belgium) and Dragonfly v.2021.1.0.977 (Object Research Systems Inc., 2021, Montreal, Canada) for analysis and visualization. Raw CT scan data for YJDM 00008 is available on MorphoSource (https://www.morphosource.org/concern/media/000361358?locale=en) to qualified researchers.

Axial twisting of the maxillary dentition in YJDM 00008 (see below) was visualized and measured digitally, as in D'Emic \& Carrano (2020). To ensure accurate measurement of these angles for each tooth, the $\mathrm{X}, \mathrm{Y}$, and $\mathrm{Z}$ viewing planes were re-oriented in Dragonfly v.2021.1.0.977 so as to align with the mesiodistal, apicobasal, and labiolingual axes of the tooth, and the angle of twisting was measured across the entirety of the tooth crown. This approach was also used to confirm the absence of axially twisted dentition in several other eusauropod taxa for which CT scan data were available (Bellusaurus IVPP V17768.1; an indeterminate diplodocine USNM 2672; Camarasaurus CM 11338; Euhelopus PMU 24705/1a-b; an undescribed mamenchisaurid skull IVPP V27936; Sarmientosaurus MDT-PV 2).

Anatomical terminology for major components of the maxilla follows Wilson et al. (2016). We also coin a new term, internal antorbital fossa, for the fossa on the maxillary portion of the antorbital cavity that spans the medial surface of the narial process and the dorsal surface of the main body of the maxilla. Phylogenetic definitions used in this study are given in Table 1.

Maxilla. YJDM 00008 comprises a partial left maxilla with some replacement teeth in situ (Figs. 2-6). The preserved length of the maxilla is $28 \mathrm{~cm}$, and we estimate the complete maxilla to have been about $30 \mathrm{~cm}$ long along its ventral margin. The maxilla is thus shorter than in

Brachiosaurus and Giraffatitan (about $40 \mathrm{~cm}$ long; Janensch, 1935; Carpenter \& Tidwell, 1998; D'Emic \& Carrano, 2020) but longer than the maxilla of Euhelopus (approximately $18 \mathrm{~cm}$ long; Poropat \& Kear, 2013), suggesting that the skull of YJDM 00008 is intermediate in size between Euhelopus and Giraffatitan.

The partial left maxilla of YJDM 00008 can be broadly divided into two parts: a relatively thick, dentigerous ventral portion, and a more delicately constructed dorsal portion. The former part of the maxilla is largely intact, except for the missing posteriormost and ventral parts of the 
184 maxillary body, including that part that would have articulated with the jugal (Figs. 2-3). The

185 dorsal part of the maxilla is more fragmentarily preserved, and is missing the narial (= ascending;

186 posterodorsal) process and the lateral surface of the maxilla in the region of the antorbital

187 fenestra, the margins of which are not intact. The dorsal part of the maxilla has also suffered

188 some taphonomic distortion, such that this region bows outward and overhangs the lateral

189 surface of the ventral, dentigerous portion of the maxilla.

190 Externally, the dorsal portion of the maxilla exhibits a slight concavity, bounded

191 anteroventrally by a crescentic rim, that demarcates the anterior end of the narial fossa. At its

192 anterior extreme, the narial fossa is pierced by a large foramen that we interpret to be the anterior

193 maxillary foramen. An anterolaterally positioned narial fossa is also seen in Camarasaurus

194 (Madsen, McIntosh, \& Berman, 1995), Euhelopus (Poropat \& Kear, 2013) and Brachiosauridae

195 (e.g. Brachiosaurus, Carpenter \& Tidwell, 1998; Giraffatitan, Janensch, 1935; Europasaurus,

196 Sander et al., 2006; Marpmann et al. 2015; Abydosaurus, Chure et al., 2010), unlike in late-

197 branching titanosauriforms and diplodocoids, in which the naris and the narial fossa are more

198 posterodorsally positioned on the maxilla and located on the top of the skull ( Curry Rogers \&

199 Forster, 2004; Whitlock, 2011; Zaher et al., 2011; Tschopp \& Mateus, 2017). Anterodorsally, the

200 maxilla bears an elongate sulcus that would have accommodated the narial (= ascending) process

201 of the premaxilla. A stout anteromedial (= premaxillary; anterodorsal) process projects from the

202 maxilla immediately ventromedial to this sulcus. The anteromedial process articulated with the

203 premaxilla, and in life would have received a posteromedially-directed process from the latter

204 bone, for which it bears a groove on its dorsal surface. At the base of the anteromedial process is

205 a semi-circular notch that corresponds to the maxillary half of the subnarial foramen (Figs. 2-3),

206 the other half of which would have been provided by a complementary notch in the premaxilla.

207 The subnarial foramen appears to have been mediolaterally oriented and visible in lateral view,

208 as in diplodocoids, late-branching titanosauriforms (Wilson et al., 2016), and Euhelopus (Poropat

$209 \&$ Kear, 2013) but unlike the dorsal orientation of this foramen in neosauropods like

210 Camarasaurus (CM 11338; Madsen et al., 1995) and Giraffatitan (Janensch, 1935; Madsen et

211 al., 1995).

212

213

214

215

216

217

218

219

220

221

222

223

224

225

226

227

228

229

Although the posterior end of the maxillary main body is incomplete, it is clear that the specimen lacks the strongly tapering, posteriorly directed jugal process of some late-branching titanosauriforms (e.g., Rapetosaurus, Curry Rogers \& Forster 2004; Tapuiasaurus, Wilson et al. 2016). Instead, the specimen bears the plesiomorphically blocky posterior end of the maxilla that characterizes taxa such as Giraffatitan (MB.R.2180.2; Janensch 1935), Euhelopus (Wilson \& Upchurch 2009; Poropat \& Kear 2013), and Sarmientosaurus (Martínez et al. 2016). Dorsally, the posterior end of the maxilla is marked by a trough, which provided entry into the dorsal alveolar canal for the maxillary vessels and dorsal alveolar nerve (White 1958; Porter \& Witmer 2020). Posterior to the level of the last alveolus, the lateral wall of the dorsal alveolar canal has broken away, exposing the interior of the canal in lateral view. The presence of a preantorbital foramen/fenestra cannot be confirmed, as the relevant portion of the dorsal alveolar canal that would have given rise to it ventrolaterally is missing. It is noteworthy, however, that a broad, shallow fossa embays the lateral surface of the maxilla immediately ventral to the broken dorsal alveolar canal, as such a fossa is present in some taxa with well-developed preantorbital openings (e.g., Giraffatitan MB.R.2180.2; Tapuiasaurus Wilson et al. 2016). The presence of a continuous, plate-like wall of bone along the length of the palatal shelf (preserved intact or otherwise evidenced by a broken edge) suggests that the preantorbital opening, if present, was separated from the antorbital cavity, in contrast to the condition in various diplodocids (e.g.,

Peer) reviewing PDF | (2021:04:60622:1:0:NEW 7 Jul 2021) 
230 Galeamopus Tschopp \& Mateus 2017) and titanosaurians (e.g., Nemegtosaurus Wilson 2005) in

231

232

233

234

235

236

237

238

239

240

241

242

243

244

245

246

247

248

249

250

251

252

253

254

255

256

257

258

259

260

261

262

263

264

265

266

267

268

269

270

271

272

273

274

275

which the preantorbital opening is broadly continuous with the antorbital cavity.

On the medial surface of the maxilla, at the junction of its dorsal and ventral portions, is the internal antorbital fossa. This fossa is bounded ventrally by the palatal shelf and anteriorly and laterally by that portion of the maxilla that floors the narial fossa externally and gives rise to the narial process. The latter part of the maxilla is thin-walled and plate-like where it meets the palatal shelf. The lateral wall of the internal antorbital fossa meets the palatal shelf at an abrupt, approximately 90-degree angle. The sharp angulation of the ventrolateral boundary of the internal antorbital fossa contrasts with the relatively smooth transition between the ventral and lateral margins of the fossa in various other sauropods (e.g., Camarasaurus (Madsen et al., 1995, Figs 9-11), Euhelopus (Poropat \& Kear, 2013, Fig. 2), Rapetosaurus (Curry Rogers \& Forster, 2004, Figs 3-4)), though it is possible that the sharpness of this angle has been exaggerated by taphonomic distortion.

The anterior margin of the internal antorbital fossa extends close to the anterior one-third of the maxillary tooth row, which is also seen in Euhelopus (Wilson \& Upchurch, 2009; Poropat \& Kear, 2013). In Bellusaurus (Moore et al., 2018), Camarasaurus (Madsen et al., 1995), Brachiosauridae such as Brachiosaurus, Giraffatitan, and Abydosaurus (Janensch, 1935; Carpenter \& Tidwell, 1998; Chure et al., 2010) and possibly Rapetosaurus (Curry Rogers \& Forster, 2004), the anterior margin of the internal antorbital fossa only extends to roughly half the length of the tooth row. The medial view of the maxilla is poorly described or hard to observe in other taxa, and thus the relative anterior extent of the internal antorbital fossa is difficult to characterize more broadly. At the posteromedial end of the palatal shelf there is a rough area which might be the contact surface for the palatine.

In medial view, there are ten nearly complete alveoli with in situ dentition (Figs. 3, 5). The lateral and posterior walls of an additional alveolus are preserved at the anterior end of the maxilla, indicating a total of at least 11 maxillary alveoli. For comparison, Camarasaurus has 810 maxillary teeth (Madsen et al., 1995; Ikejiri et al., 2005), the brachiosaurids Europasaurus (Marpmann et al., 2015), Abydosaurus (Chure et al., 2010), Giraffatitan (Janensch, 1935), and Brachiosaurus (Carpenter \& Tidwell, 1998; D'Emic \& Carrano, 2020) have 12-13, 10, 12, and 14 teeth, respectively, the early-branching titanosauriform Euhelopus has approximately 9 to 10 ( Wilson \& Upchurch, 2009; Poropat \& Kear, 2013), the late-branching titanosauriform Tapuiasaurus (Zaher et al., 2011; Wilson et al., 2016) has 12, and the Asian late-branching titanosauriform taxa Nemegtosaurus and Quaesitosaurus have only 8 or 9 maxillary teeth (Kurzanov \& Bannikov, 1983; Wilson, 2005). The maxillary teeth of the specimen are perpendicular to the ventral margin of the maxilla, as in Brachiosauridae and Camarasaurus (Janensch, 1935; Madsen et al., 1995; Carpenter \& Tidwell, 1998; Sander et al., 2006; Marpmann et al., 2015) as well as late-branching titanosauriforms such as Tapuiasaurus, Nemegtosaurus, Quaesitosaurus and Rapetosaurus (Kurzanov \& Bannikov, 1983; Curry Rogers \& Forster, 2001; Curry Rogers \& Forster, 2004; ; Wilson, 2005; Zaher et al., 2011; Wilson et al., 2016; ). By contrast, the maxillary teeth are anteroventrally oriented in Euhelopus (Wilson \& Upchurch, 2009; Poropat \& Kear, 2013), and a similar condition is also observed in Diplodocoidea, such as in Apatosaurus (Berman \& McIntosh, 1978), Dicraeosaurus (Janensch, 1935), Kaatedocus (Tschopp \& Mateus, 2013), Galeamopus (Tschopp \& Mateus, 2017) and Diplodocus (Wilson \& Sereno, 1998). Maxillary alveoli are approximately evenly spaced, with anterior alveoli slightly larger than posterior ones. The last 6 alveoli have an anteroposterior width of 10 to $15 \mathrm{~mm}$, but the anterior 4 alveoli can reach 18 to $20 \mathrm{~mm}$. Slightly above the

PeerJ reviewing PDF | (2021:04:60622:1:0:NEW 7 Jul 2021) 
276 alveoli (approximate $10 \mathrm{~mm}$ dorsal to them) on the medial side, there are a series of deep

277 neurovascular foramina - the replacement foramina - through which the replacement teeth are

278 visible.

279

280

281

Dentition. All functional teeth are missing from the specimen, and at least two generations of replacement teeth are preserved (Fig. 5). The teeth are positioned in the anterior half of the

282

283

284

285

286

287

288

289

290

291

292

293

294

295

296

297

298

299

300

301

302

303

304

305

306 maxilla, though the anterior positioning of the teeth is not as extreme as in Diplodocoidea (Janensch, 1935; Wilson \& Sereno, 1998; Berman \& McIntosh, 1978; Sereno et al., 2007; Tschopp \& Mateus, 2013, 2017). The anterior teeth are slightly larger than the posterior ones, and the teeth are curved lingually.

The maxillary teeth are parallel-sided in labial view, lacking the mesiodistal expansion of the crown that is plesiomorphic for sauropod dentition. The tooth crowns taper apically, and in cross-section are roughly D-shaped, with a strongly convex labial face, as in Brachiosauridae (Janensch 1935; Carpenter \& Tidwell, 1998; Sander et al., 2006; Chure et al., 2010; Marpmann et al. 2015), various early-branching somphospondylans (e.g., Bonaparte et al., 2006; Rose, 2007; Torcida Fernández-Baldor et al., 2017), and Euhelopodidae ( Wilson \& Upchurch, 2009; D'Emic, 2012; Poropat \& Kear, 2013, and unlike the subcylindrical crowns found in laterbranching somphospondylans and most Diplodocoidea (Berman \& McIntosh, 1978; Kurzanov \& Bannikov, 1983; Curry Rogers \& Forster, 2001; Curry Rogers \& Forster, 2004; Wilson, 2005; Whitlock, 2011; Zaher et al., 2011). The lingual surface of the crown is subtly divided into two faces - a wider, slightly concave mesial face and a narrower, relatively flat distal face - that are gently offset from one another (Figs. 5-6). Where these two lingual faces meet there is a low, longitudinal bulge. We interpret this feature to be homologous to the apicobasal lingual ridge that is plesiomorphic for sauropods and is present in some brachiosaurids, Sauroposeidon, Astrophocaudia, Sibirotitan, Euhelopus, and most non-neosauropod sauropod teeth (Barrett et al., 2002; Rose, 2007; D'Emic, 2013; Mannion et al. 2013; Averianov et al., 2018), although its development in YJDM 00008 is markedly weaker than in most other taxa with a lingual ridge. The mesial and distal edges of the crown are relatively smooth compared to the wrinkled surface of the lingual and labial surfaces. The maxillary teeth are twisted axially (Fig. 6, Table 2), a feature that has been recovered as a unique synapomorphy of Brachiosauridae or a slightly less inclusive clade (e.g., D'Emic, 2012; Mannion et al., 2013, 2017; Marpmann et al., 2015; D'Emic \& Carrano, 2020). The slenderness index (SI; ratio of length of crown to mesiodistal width (Upchurch, 1998)) for YJDM 00008 ranges from approximately 2.30 to 3.56 (Table 2). This range is similar to that observed in various brachiosaurids $(2.2-2.68$ in Vouivria; $1.72-2.93$ in

310 Giraffatian; 2.4-3.25 in Abydosaurus; 2.3 in Soriatitan) (Chure et al., 2010; Mannion et al., 311 2017; Royo-Torres et al., 2017), Malawisaurus (3.3-3.5; Gomani, 2005), Sarmientosaurus (2.0312 3.7; Martínez et al., 2016) and most non-lithostrotian somphospondylans, such as Europatitan 313 (2.2; Torcida Fernández-Baldor et al., 2017), Euhelopus (2.2-3.3; Chure et al., 2010),

314 Yongjinglong (1.65-3.93; Li et al., 2014), and Huabeisaurus (3.36-3.46; D'Emic et al., 2013). In

315 Phuwiangosaurus and lithostrotians other than Malawisaurus, the teeth are markedly more

316 slender than in YJDM 00008: for example, the SI exceeds 5 in Rapetosaurus (Curry Rogers \&

317 Forster, 2004) and Pitekunsaurus (Filippi \& Garrido, 2008), and ranges from 3.3 to 6.3 in

318 Phuwiangosaurus (Chure et al., 2010), from 4.1 to 5.9 in the upper teeth of Tapuiasaurus (Zaher et al., 2011; Wilson. et al., 2016), and from 3.9-4.67 in Nemegtosaurus (Wilson, 2005).

The CT scans show that two replacement teeth are present in each tooth socket (Fig. 5BD), as in Bellusaurus (Moore et al., 2018) and Brachiosaurus (D'Emic \& Carrano 2020). The 
322

323

324

325

326

327

328

329

330

331

332

333

334

335

336

337

338

339

340

341

342

343

344

345

346

347

348

349

350

351

352

353

354

355

356

357

358

359

360

361

362

363

364

365

366

367

younger generation of replacement teeth is distodorsal to and overlapped labially by the more mature generation. The crowns of the younger generation of replacement teeth are oriented mesioventrally (Fig. 5B-D). Some other neosauropods exhibit greater numbers of replacement teeth. Among macronarians, Camarasaurus and the 'Río Negro titanosaur' possess three replacement teeth per alveolus (Coria \& Chiappe, 2001; D’Emic et al., 2013). This condition differs from that of Diplodocoidea, which present a high tooth replacement rate and more generations of replacement teeth (e.g., five in Diplodocus; 10 in Nigersaurus) ( Sereno, \& Wilson, 2005; D’Emic et al., 2013).

\section{Systematic Paleontology}

Dinosauria Owen, 1842

Saurischia Seeley, 1887

Sauropoda Marsh, 1878

Macronaria Wilson \& Sereno, 1998

Macronaria indet.

Material. YJDM 00006, a fragmentary right dentary.

Locality and horizon. As for YJDM 00008 (see above).

\section{Description and comparisons}

YJDM 0006 comprises a fragmentary right dentary missing much of its anterior, dentigerous ramus (Fig. 7). The preserved portion bears four alveoli and corresponding replacement foramina. The dentary bifurcates posteriorly into posterodorsal and posteroventral processes. A roughened area for reception of the surangular marks the lateral surface of the posterodorsal process. A forked posteroventral process - a feature that characterizes Tapuiasaurus (Wilson et al., 2016) and brachiosaurids other than Europasaurus (Janensch, 1935; Chure et al., 2010; Marpmann et al., 2015; D'Emic \& Carrano, 2020) and that results from the development of a small accessory process on the posteroventral process - appears to be absent in YJDM 0006. However, because the posterior portion of the posteroventral process and part of its dorsal margin are missing, it remains possible that the accessory process was present but relatively posteriorly positioned.

All functional teeth are missing, but three replacement teeth are preserved in situ and visible externally. One of the replacement teeth is in the last alveolus and the other two are in the penultimate alveolus, indicating at least two generations of replacement teeth. The dentary tooth crowns are parallel-sided, taper apically, and have a D-shaped cross-section, as in YJDM 00008 and in macronarians plesiomorphically. It is not possible to discern whether the dentary teeth bore denticles. The mesiodistal diameters of the dentary tooth crowns are notably smaller than those of roughly corresponding maxillary teeth in YJDM 00008: for posterior positions in each element, the dentary tooth is half as wide as the maxillary tooth (approximately $4 \mathrm{~mm}$ in the last two dentary replacement teeth vs. $8.43 \mathrm{~mm}$ in the tenth maxillary replacement tooth). An unequally-sized upper and lower dentition is a widely distributed feature among neosauropods (Chure et al., 2010; Mannion et al., 2013), including diplodocoids (e.g., Diplodocus Holland, 1924), the late-branching brachiosaurid Abydosaurus (Chure et al., 2010), and various somphospondylans (e.g. Euhelopus, Poropat \& Kear, 2013; Sarmientosaurus, Martínez et al., 2016; Nemegtosaurus Wilson 2005; Tapuiasaurus, Wilson et al. 2016). Thus, if the maxilla and

PeerJ reviewing PDF | (2021:04:60622:1:0:NEW 7 Jul 2021) 
368 dentary are hypothesized to belong to a single individual, then their disparate dentitions could be

369

370

371

372

373

374

375

376

377

378

379

380

381

382

383

384

385

386

387

388

389

390

391

392

393

394

395

396

397

398

399

400

401

402

403

404

405

406

407

408

409

410

411

412

413 consistent with a wide array of phylogenetic positions within Neosauropoda. However, this possibility should be tempered by two cautionary points. First, although an unequally-sized upper and lower dentition occurs throughout Neosauropoda, this feature is nonetheless sparsely known, as it can only be confirmed in specimens with sufficient single-individual cranial material. Thus, its true distribution across Neosauropoda remains uncertain. Second, unerupted replacement teeth were still in the process of developing when the animal(s) died, and their measured mesiodistal diameters may not reflect the size ratios of the fully erupted, functional dentition, especially if the teeth being compared are measured at different stages of growth. This also bears consideration when noting that the size disparity between the maxillary and dentary replacement teeth of the Yanji cranial material is somewhat greater than that observed in various other taxa for which an association of upper and lower jaws is certain. Whereas the posterior replacement teeth in the Yanji maxilla are twice as wide as complementary teeth in the dentary, this ratio is lower for the functional teeth of other neosauropods with unequal upper and lower dentitions, including an indeterminate diplodocine ( 1.4; USNM 2672), Abydosaurus $(\sim 1.3$; DINO 17848), Euhelopus ( 1.3; PMU 24705/1a-b), Sarmientosaurus ( 1.7; Martínez et al., 2016), Tapuiasaurus ( 1.5; Wilson et al., 2016), and Nemegtosaurus ( 1.5; Wilson, 2005). Under the assumption that the maxilla and dentary belong to a single individual, the relatively large disparity in upper and lower tooth size in the Yanji cranial material could indicate that complementary replacement teeth are imperfect size proxies for mature teeth, or that this animal had a potentially autapomorphic degree of tooth size disparity. Alternatively, the dentary may belong to a smaller-bodied individual than the one represented by the maxilla, and may represent a different taxon. The available information does not allow us to distinguish between these possibilities.

\section{Phylogenetic materials and methods.}

We tested the phylogenetic affinities of the Yanji cranial material using a morphological character matrix based on that of Poropat et al. (2021). Although we conservatively consider the maxilla (YJDM 00008) and dentary (YJDM 00006) to belong to separate individuals, we tested the effect that including these two specimens together as a single operational taxonomic unit (OTU) has on the results of our phylogenetic analyses. The maxilla (YJDM 00008) could be scored for $17(3 \%)$ of the 552 characters in the Poropat et al. (2021) matrix. Inclusion of the dentary in the same OTU allowed two additional characters to be scored: character 103, concerning the forked posteroventral process of the dentary (scored as absent), and character 107, concerning unequally sized diameters of upper and lower dentition (scored as present). Although it is possible that a forked posteroventral process was present in the Yanji dentary (see above), we scored this feature as absent (as opposed to '?') because such a score should provide a more stringent test of the possible brachiosaurid affinities of the Yanji cranial material, given that brachiosaurids other than Europasaurus possess this process.

In addition to the Yanji cranial material, we also added to the Poropat et al. (2021) matrix recently redescribed brachiosaurid cranial material from the Late Jurassic Morrison Formation of Garden Park, Colorado, USA (USNM 5730; Marsh, 1891; Carpenter \& Tidwell 1998; D’Emic \& Carrano 2020). In a series of preliminary analyses (not shown) in which USNM 5730 and the Brachiosaurus OTU of Poropat et al. (2021) were scored separately, USNM 5730 was consistently recovered as a brachiosaurid, under both equal and extended implied weights parsimony analysis and with and without the inclusion of the Yanji cranial material. In accord

PeerJ reviewing PDF | (2021:04:60622:1:0:NEW 7 Jul 2021) 
414 with the proposed existence of a single brachiosaurid species in the Morrison Formation

415 (D'Emic \& Carrano, 2020), we included USNM 5730 in the Brachiosaurus altithorax hypodigm

416 for the phylogenetic analyses conducted here.

417 The final data matrix consisted of 552 characters scored for 126 OTUs (Supplementary I)

418 and was subjected to both equal weights (EW) and extended implied weights (EIW) parsimony

419 analysis (Goloboff, 2014) in TNT v.1.5 (Goloboff \& Catalano 2016). We ran two separate

420 versions of these analyses: one in which the maxilla was the sole representative of the Yanji

421 cranial material, and another in which the dentary was included alongside the maxilla in a single

422 OTU. Character ordering, taxon sampling, and down-weighting of homoplasy followed Poropat

423 et al. (2021). Eighteen characters (11, 14, 15, 27, 40, 51, 104, 122, 147, 148, 195, 205, 259, 297 ,

424 426, 435, 472, 510) were treated as ordered. Ten unstable taxa (Astrophocaudia, Australodocus,

425 Brontomerus, Fukuititan, Fusuisaurus, Liubangosaurus, Malarguesaurus, Mongolosaurus,

426 Ruyangosaurus, and the 'Cloverly titanosauriform') were excluded a priori from the EW

427 parsimony analysis; two of these (Ruyangosaurus and the 'Cloverly titanosauriform') were re-

428 instated as active taxa for the EIW analysis. In the latter analysis, we applied a concavity

429 constant $(\mathrm{k})$ of nine.

430 For both EW and EIW analyses, we used 'New Technology' search algorithms to identify

431 the set of most parsimonious trees (MPTs). Fifty search replications were used as a starting point

432 for each hit, and were run until the best score was hit 10 times, using random and constraint

433 sectorial searches under default settings, five ratchet iterations and five rounds of tree fusing per

434 replicate (' $x$ mult $=$ replications 50 hits $10 \mathrm{css}$ rss ratchet 5 fuse 5'). The initial set of MPTs

435 recovered by the analysis was subjected to an additional round of tree bisection and reconnection

436 (TBR) branch swapping to exhaustively sample all equal-length trees. Alternative placements of

437 the Yanji cranial material were identified using the resols command. Character support was

438 assessed in TNT using the apo command and in Mesquite 3.61 (Maddison \& Maddison, 2019).

439

440

441

442

443

444

445

446

447

448

449

450

451

452

453

454

455

456

457

458

459

\section{Phylogenetic Results}

Maxilla-only OTU. The EW parsimony analysis resulted in 318,737 trees of 2665 steps (consistency index $=0.218$; retention index $=0.398$ ). The Yanji maxilla was found to be a neosauropod of unclear affinities: it is equally well-supported as 1) a non-diplodocimorph diplodocoid, 2) a well-nested brachiosaurid most closely related to a clade including Soriatitan, Venenosaurus, Cedarosaurus, and Abydosaurus, and 3) an early-branching euhelopodid (Fig. 8).

Parsimony analysis under EIW produced 2,520 trees of 115.80653 steps. The strict consensus of these trees resolves the Yanji maxilla as a brachiosaurid. Although the composition and early branching pattern of Brachiosauridae differ between the EW and EIW analyses, in both sets of MPTs the Yanji maxilla is part of a well-nested group comprising Soriatitan,

Venenosaurus, Cedarosaurus, and Abydosaurus (Fig. 9).

Maxilla+dentary OTU. Inclusion of the dentary in the Yanji OTU did not affect tree length for the EW parsimony analysis, but produced many more MPTs (more than one million). Unlike the maxilla-only analysis, the maxilla+dentary OTU is not found to be a brachiosaurid (at least not in the one million MPTs that we collected), and is instead only recovered as either a non-diplodocimorph diplodocoid or an early-branching euhelopodid.

Parsimony analysis under EIW produced 1,890 trees of 115.84075 steps. The strict consensus of these trees is identical to that of the maxilla-only EIW analysis, except that the Yanji cranial material is recovered as an earlier-branching brachiosaurid, in one of three positions: as sister to Vouivria, one node stem-ward of Vouivria, or one node apical to Vouivria.

PeerJ reviewing PDF | (2021:04:60622:1:0:NEW 7 Jul 2021) 
460 This earlier-branching position results from scoring a forked posteroventral process of the

461 dentary as absent, as this feature is a synapomorphy of the clade that includes Brachiosaurus,

462 Giraffatitan, and Abydosaurus.

463

464

\section{Discussion}

465

466

467

Previous evidence for Asian brachiosaurids

Fossil evidence has occasionally been advanced to suggest the presence of brachiosaurids in the Late Jurassic or Early Cretaceous of Asia, but these hypothesized occurrences have either not held up to subsequent scrutiny, or at best provide only equivocal support for Asian brachiosaurids.

470

471

Based on pre-cladistic morphological comparisons emphasizing tooth crown shape, the

472

473

474

475

476

477

478

479

480

481

482

483

484

485

486

487

488

489

490

491

492

493

494

495

496

497 Late Jurassic (Oxfordian) sauropod Bellusaurus, from the Shishugou Formation of northwest China, was initially assigned to its own subfamily (Bellusaurinae) within the Brachiosauridae, then considered part of the superfamily Bothrosauropodidea (Dong, 1990). Subsequent work has failed to support brachiosaurid kinship for Bellusaurus. Although the taxon may potentially represent a neosauropod (e.g., Upchurch et al., 2004; Carballido et al., 2014; Moore et al., 2018, 2020; but see, e.g., Wilson \& Upchurch, 2009; Mo, 2013; Mannion et al., 2019b), no analysis has ever recovered Bellusaurus as a brachiosaurid, and Bellusaurus lacks many of the synapomorphies that unite Brachiosauridae and its subclades, including twisted maxillary dentition.

Similarities to Bellusaurus led Ye et al. (2005) to assign the Late Jurassic Daanosaurus, from the upper beds of the Shaximiao Formation, to the Brachiosauridae, within the subfamily Bellusaurinae. Daanosaurus has yet to be included in a phylogenetic analysis capable of testing its potential relationship to brachiosaurids; the only phylogenetic analysis to date to have included Daanosaurus exclusively sampled Middle-Late Jurassic Chinese sauropods, finding the taxon to be closely related to Mamenchisaurus (Li et al., 2011). The authors of this study did not report the matrix or the methods used in their analysis, and thus the character data in support of their phylogenetic conclusions are unclear. While the relationships of Daanosaurus remain obscure, none of the available evidence indicates a close relationship to brachiosaurids. Several characteristics (e.g., opisthocoelous posterior dorsal vertebrae; a tab-like interruption of the prezygodiapophyseal lamina in middle-posterior cervical vertebrae) suggest that Daanosaurus may be a mamenchisaurid (AJM, pers. obs. 2015; Mannion et al., 2013; Moore et al., 2020), although macronarian affinities have also been proposed (D'Emic, 2012).

An isolated tooth from the Early Cretaceous (Barremian-Aptian) Jinju Formation of South Korea was cited as the first evidence for Asian brachiosaurids on the basis of a chisel-like wear facet on its lingual surface (Lim et al., 2001). Subsequent consideration of the specimen by Barrett et al. (2002) disputed the presence of this form of wear facet and rejected its referral to Brachiosauridae, but concurred that the element likely belongs to an early-branching titanosauriform. Other isolated sauropod teeth from the Berriasian-Hauterivian (Barrett et al., 2002) and the Barremian (Saegusa \& Tomida, 2011) of Japan exhibit a mosaic of features that

500

501

502

503

504

505 has been considered potentially consistent with, but not diagnostic for, brachiosaurid affinities, although it should be noted that neither these teeth, nor the isolated tooth from the Jinju Formation, have been described as exhibiting axial twisting, the only unambiguous synapomorphy of brachiosaurid dentition.

The Chinese sauropod Qiaowanlong, comprising a partial postcranial skeleton from the late Early Cretaceous (Aptian) Xiagou Formation (You et al., 2019), was initially described as an 
506 Asian brachiosaurid based largely on comparisons to Sauroposeidon (then considered a

507 brachiosaurid) (You \& Li, 2009). However, the morphological basis for this referral evaporated

508 when subjected to phylogenetic analysis by Ksepka \& Norell (2010), who recovered

509 Qiaowanlong as a somphospondylan, as have all subsequent authors (e.g., D'Emic, 2012;

510 Mannion et al., 2013; Carballido et al., 2017; see also Mannion, 2011).

$511 \quad$ Thus, all previous fossil evidence has fallen shy of demonstrating the presence of

512 brachiosaurids in Asia. As we elaborate in the following section, we consider YJDM 00008 to

513 provide the most compelling evidence to date of an Asian brachiosaurid, while acknowledging

514 that the fragmentary nature of the specimen requires that this hypothesis be treated cautiously,

515 pending future discoveries in the Longjing Formation.

516

517

518

519

520

521

522

523

524

525

526

527

528

529

530

531

532

533

534

535

536

537

538

539

540

541

542

543

544

545

546

547

548

549

550

551

\section{Phylogenetic affinities of the Yanji maxilla}

In the discussion that follows, we focus on the results of the maxilla-only phylogenetic analyses. Although the results of the maxilla-only and maxilla+dentary analyses are not radically different, we nonetheless favor the former over the latter, for two reasons. First, because the maxilla and dentary were retrieved post-exhumation from heaps of excavated sediment that also included other vertebrate specimens (see above), any evidence for association between these two elements has been lost. The most conservative approach, therefore, is to treat them separately. Second, although inclusion of the dentary alongside the maxilla in a single OTU allows two additional characters to be scored, the scores for these characters are somewhat speculative, as discussed above. Given this uncertainty, scoring these characters is useful primarily to the extent that it incorporates the maximum possible character conflict that may exist for the OTU, and thus more stringently tests the hypothesis that the Yanji cranial material belongs to a brachiosaurid a hypothesis that otherwise rests on a single character state (see below). Under EIW parsimony, our preferred mode of phylogenetic inference, the Yanji cranial material is found to be a brachiosaurid with or without inclusion of the dentary, indicating that the potential character conflict introduced by the dentary does not overwhelm the support for brachiosaurid affinities that is afforded by the maxilla. We thus focus on the results of our maxilla-only analyses, while acknowledging the inherent limitations of analyzing fragmentary fossils. Near the end of this section, we discuss additional caveats that attend interpretation of YJDM 00008 as a brachiosaurid.

Both the EW and EIW parsimony analyses agree that the Yanji maxilla belongs to a neosauropod. This identification is supported by the presence in YJDM 00008 of parallel-sided dentition (character 108), a feature that is resolved as a synapomorphy of Neosauropoda (EW) or Neosauropoda + (Camarasaurus + Lourinhasaurus) $($ EIW). The EW parsimony analysis provides equivocal support for the Yanji taxon as a brachiosaurid, a non-diplodocimorph diplodocoid, or a euhelopodid (Fig. 8). Character support for the latter two positions is limited to a single, homoplastically distributed feature: possession of a laterally-visible subnarial foramen (character 75). A laterally-visible subnarial foramen reflects the absence of a markedly depressed narial fossa and is plesiomorphic for Eusauropoda, present in Shunosaurus and secondarily reacquired in Euhelopus, lithostrotians other than Malawisaurus (= Nemegtosaurus, Rapetosaurus, and Tapuiasaurus), and either Diplodocimorpha or Diplodocoidea (depending on whether character optimization is assumed to occur under delayed or accelerated transformation, respectively).

While the lateral exposure of the subnarial foramen suggests possible diplodocoid affinities for YJDM 00008, numerous features, mostly of the dentition, exclude the specimen 
552 from Diplodocimorpha. These include a relatively smooth dentigerous portion of the lateral 553 surface of the maxilla (character 288; this region is marked by deep, dorsoventrally elongate 554 vascular grooves in diplodocimorphs and Nemegtosaurus); a Slenderness Index of $<4.0$ 555 (character 11), D-shaped mid-crown cross-sections (character 109; these are cylindrical in 556 diplodocimorphs and Titanosauria), tooth crowns with concave lingual surfaces (character 110; these are convex in diplodocimorphs, Titanosauria, Abydosaurus, and Phuwiangosaurus), an apicobasally-oriented lingual ridge (character 111; this is only very weakly developed in YJDM 00008 and is absent in Jobaria, diplodocimorphs, some brachiosaurids, and most somphospondylans), and fewer than three replacement teeth per alveolus (character 453). The absence of cranial material known for Amphicoelias or either species of Haplocanthosaurus allows the Yanji maxilla to be recovered in all possible positions available to a nondiplodocimorph diplodocoid (Fig. 8). Such a hypothesis for the Yanji maxilla would extend the temporal range of non-diplodocimorph diplodocoids by approximately 45 million years, and would indicate that a heretofore unsampled lineage of diplodocoids survived into the middle Cretaceous. Until recently, evidence for Asian diplodocoids was scant and controversial (Upchurch \& Mannion, 2009; Whitlock et al., 2011; Xu et al., 2018). The discovery of the early Middle Jurassic dicraeosaurid Lingwulong from China, the first definitive Asian diplodocoid and the oldest known neosauropod, indicates that diplodocoids dispersed into or originated from East Asia while Pangaea was a contiguous landmass (Xu et al., 2018), and may presage future discoveries of the group in Asia. Nevertheless, the lack of more compelling diplodocoid/diplodocimorph synapomorphies in the maxilla and dentition of YJDM 00008, the extreme temporal and phylogenetic remove between YJDM 00008 and Lingwulong, and the paucity of convincing evidence for diplodocoids in the Early Cretaceous of Asia make referral of YJDM 00008 to Diplodocoidea unlikely.

A hypothesis of euhelopodid affinities for the Yanji maxilla is more consistent with the known spatiotemporal ranges of neosauropod dinosaurs. Whereas no undisputed diplodocoids are presently known in the Early Cretaceous of Asia (Upchurch \& Mannion, 2009; Whitlock et al., 2011; Xu et al. 2018), numerous non-titanosaurian somphospondylan taxa have been recovered from this interval, with members of the Euhelopodidae - an East Asian radiation of somphospondylans - being particularly well-represented (D'Emic, 2012; Mannion et al. 2013, 2019a). Like the hypothesis of diplodocoid kinship, however, support for a position at the base of Euhelopodidae relies solely on the presence of a laterally-visible subnarial foramen, a homoplastically distributed feature that is thus far known only for the eponymous Euhelopus among euhelopodids. Recent comparative anatomical and phylogenetic work has called into question the macronarian affinities of Euhelopus (Moore et al. 2020), suggesting that phylogenetic results relying solely on features shared with that taxon should perhaps be treated cautiously.

A consideration of the evolutionary scenarios implied by competing topological positions of YJDM 00008 leads us to favor brachiosaurid affinities for the specimen. The EIW parsimony analysis and a subset of the MPTs from the EW analysis indicate that the Yanji taxon is a wellnested brachiosaurid. Support for brachiosaurid affinities for YJDM 00008 rests on a single feature - the presence of axially twisted maxillary teeth (character 114; Figs. 6-7) - which, under EW parsimony analysis, provides no more or less support for brachiosaurid affinities than a laterally visible subnarial foramen does for diplodocoid and euhelopodid kinship. Unlike a laterally visible subnarial foramen, however, twisted maxillary dentition is a characteristic that otherwise lacks homoplasy within Eusauropoda, and has been universally recovered as an 
598

599

600

601

602

603

604

605

606

607

608

609

610

611

612

613

614

615

616

617

618

619

620

621

622

623

624

625

626

627

628

629

630

631

632

633

634

635

636

637

638

639

640

641

642

643 unambiguous synapomorphy (sensu Tschopp et al. 2015) of Brachiosauridae or a slightly less inclusive clade by previous authors (e.g., D'Emic, 2012; Mannion et al. 2013; 2017; D'Emic et al., 2016; Carballido et al., 2020). The high consistency of this character ( $\mathrm{CI}=1$ in all previous analyses) accounts for why the EIW parsimony analysis favors only brachiosaurid affinities for YJDM 00008: parsimony under EIW weights characters in proportion to the homoplasy they incur on the trees being compared, and thus treats brachiosaurid kinship for YJDM 00008 as more parsimonious than either diplodocoid or euhelopodid affinities because such a relationship avoids homoplasy in a character that is otherwise perfectly hierarchical (i.e. twisted maxillary dentition), at the expense of adding a step to an unavoidably homoplasious character (i.e. laterally-visible subnarial foramen). We agree with the epistemological arguments in favor of such trade-offs (Goloboff 1993), and in light of recent simulations showing that EIW outperforms EW parsimony (Goloboff et al., 2017), prefer the former over the latter as a mode of phylogenetic inference. In the absence of compelling character conflict with other brachiosaurids or evidence for a wider distribution of strongly $\left(30-45^{\circ}\right)$ twisted dentition outside of Brachiosauridae, we thus consider the available data to be most consistent with the hypothesis that YJDM 00008 is a brachiosaurid, diagnosed by a laterally visible subnarial foramen.

The nested position of YJDM 00008 among Cedarosaurus, Venenosaurus, Soriatitan, and Abydosaurus is supported by the absence of denticles in the dentition (character 113; observable only in the latter two taxa and YJDM 00008). Most eusauropods later-branching than Jobaria lack denticles. However, marginal enamel tuberosities were reacquired in brachiosaurids, where they are present in a grade that includes Europasaurus, Vouivria, Brachiosaurus, and Giraffatitan, and were secondarily lost in the subclade to which YJDM 00008 belongs. It should be noted, however, that at least some brachiosaurids, as well as some other sauropod taxa, appear to exhibit an uneven distribution of denticles between the upper and lower jaws. Replacement teeth preserved in the maxilla of Brachiosaurus lack denticles, whereas at least some of those in the dentary bear denticles on their mesial edge (D'Emic \& Carrano, 2020), a pattern that also characterizes Bellusaurus (Moore et al. 2018) \& Abrosaurus (Ouyang, 1989). Preservation of the visible replacement teeth in the Yanji dentary (YJDM 00006) is insufficient to determine whether denticles are present. Thus, it remains possible that the Yanji sauropod(s) bore denticles on the dentary teeth, though such a finding would not perturb support for brachiosaurid affinities.

The close relationship between YJDM 00008 and several late-branching brachiosaurids may also find support from the very weak development of an apicobasally oriented lingual ridge (character 111) in the teeth of YJDM 00008. This ridge is plesiomorphic for eusauropods (Barrett et al., 2002; Mannion et al. 2013) and is present in brachiosaurids such as Vouivria (Mannion et al. 2017) and Giraffatitan (Janensch 1935-36), but is absent in Jobaria, Diplodocoidea/Diplodocimorpha, most somphospondylans, and the brachiosaurid subclade that includes Abydosaurus and Soriatitan. While the presence of a lingual ridge in YJDM 00008 excludes it in all MPTs from the Abydosaurus + Soriatitan clade, its subtle development in the specimen is potentially consistent with the progressive evolutionary loss of the lingual ridge in a subset of brachiosaurids.

Our interpretation of YJDM 00008 as a brachiosaurid is tempered by two important caveats. First, while current evidence indicates that axially twisted maxillary dentition is an unambiguous synapomorphy of a subclade of Brachiosauridae, very little is known about maxillary evolution in non-titanosaurian somphospondylans (and next to nothing, if Euhelopus lies outside of Macronaria; Moore et al., 2020). This knowledge gap leaves open the possibility 
644 that strongly twisted maxillary teeth in fact characterize a more inclusive grade of

645 titanosauriforms or macronarians than the presently available fossil evidence would suggest.

646 Slight axial twisting has been noted for the maxillary teeth of Europasaurus (Marpmann et al.,

647 2015) - a taxon whose brachiosaurid and titanosauriform kinship remains a topic of controversy

648 (Mannion et al., 2017; Carballido et al., 2020) - as well as for a handful of non-brachiosaurid

649 titanosauriforms, including isolated teeth of Astrophocaudia (D'Emic, 2013) and distal maxillary

650 teeth of Tapuiasaurus (Wilson et al., 2016). Considered together, these observations suggest that

651 twisted dentition may be more broadly distributed within Macronaria than is presently

652 appreciated, and underscore that additional materials from early-branching somphospondylans

653 are needed in order to robustly test whether marked axial twisting $\left(\sim 30-45^{\circ}\right)$ of the maxillary

654 dentition indeed constitutes an unambiguous brachiosaurid synapomorphy.

655 Second, we have yet to identify any other clear evidence for brachiosaurids in the

656 Longshan fauna, although it should be noted that our initial observations on the other sauropod

657 fossils from the Longshan beds of the Longjing Formation are still very preliminary (being based

658 on only a subset of the total material that has been excavated) and have not been incorporated

659 into a phylogenetic analysis. Morphological details of these sauropod fossils are instead more

660 consistent with a euhelopodid or early-branching titanosaurian identity, as indicated by such

661 features as subcylindrical tooth crowns (character 109; a titanosaurian synapomorphy, also

662 present in diplodocimorphs), bifurcated postaxial cervical and anterior dorsal neural spines

663 (character 132; widely distributed in non-titanosauriform eusauropods, and present in most

664 euhelopodids, early-branching titanosaurians, and Opisthocoelicaudia), and a scapula lacking a

665 subtriangular process at both the posteroventral corner of the acromion and the anteroventral

666 edge of the scapular blade (characters $215 \& 216$; both processes are absent in Jiangshanosaurus

667 and Huabeisaurus, among other eusauropods). Although the phylogenetic affinities of other

668 sauropod material from the Longshan beds do not bear directly on the identity of YJDM 00008,

669 the possibility that the latter belongs to a brachiosaurid may become unlikely if all other material

670 from the Longshan beds is eventually shown to belong to a single somphospondylan taxon.

671 Ultimately, additional evidence for or against the presence of a brachiosaurid in the Longshan

672 fauna, and other details on the taxonomic diversity of this assemblage, await further study of

673 excavated specimens and future excavation in the Longjing Formation.

674

675

676

677

678

679

680

681

682

683

684

685

686

687

688

689

\section{Paleobiogeographic implications of Asian brachiosaurids}

Assuming brachiosaurid affinities for YJDM 00008, at least two scenarios can be posited to explain the occurrence of a middle Cretaceous Asian brachiosaurid. The first proposal interprets the presence of a brachiosaurid in the Longjing Formation as resulting from dispersal of a lineage of brachiosaurids into East Asia at some point in the Early Cretaceous (or possibly the Late Jurassic). The results of our maxilla-only phylogenetic analysis are most consistent with a close relationship between YJDM 00008 and North American brachiosaurids, and hence a North American origin for the lineage that gave rise to YJDM 00008. As discussed above, however, the character data supporting this inference are very limited, and the relationships of YJDM 00008 among brachiosaurids (or perhaps neosauropods more broadly) are likely to change with future discoveries. Here, we briefly consider alternative dispersal routes available to either North American or European ancestors of YJDM 00008; consideration of the latter possibility is warranted based on the presence of the Spanish brachiosaurid Soriatitan in the polytomy to which YJDM 00008 belongs, as well as other evidence for apparent interchange between the sauropod faunas of Europe and Asia in the Early Cretaceous (see below).

PeerJ reviewing PDF | (2021:04:60622:1:0:NEW 7 Jul 2021) 
690

691

692

693

694

695

696

697

698

699

700

701

702

703

704

705

706

707

708

709

710

711

712

713

714

715

716

717

718

719

720

721

722

723

724

725

726

727

728

729

730

731

732

733

734

735

Current information is consistent with either North America or Europe as a potential source of Asian emigrants in the Early Cretaceous (Poropat et al. 2016; Xu et al. 2018; and references therein). Considerable biogeographic and phylogenetic evidence indicates a close relationship between Asian and North American faunas in the middle Cretaceous (e.g., Russell, 1993; Cifelli et al., 1997; Chinnery-Allgeier \& Kirkland, 2010; D'Emic et al. 2010; Zanno \& Makovicky 2011; Farke et al. 2014; Brikiatis 2016; Dunhill et al. 2016; Poropat et al., 2016; Ding et al., 2020). Trans-European dispersal cannot be ruled out as an explanation for faunal similarities between Asia and North America (e.g., Chinnery-Allgeier \& Kirkland, 2010; Brikiatis, 2016; Ding et al., 2020); indeed, recent quantitative analyses of dinosaurian biogeography have emphasized Europe as a likely gateway between Asia, North America, and other landmasses in the Early Cretaceous (Dunhill et al., 2016; Ding et al., 2020), although Zanno \& Makovicky (2011) argued that trans-European dispersal between Asia and North America at this time would have been complicated by the periodic development of various geographic barriers. An alternative hypothesis entails emplacement of a Bering land bridge between Asia and North America for at least part of the Albian (Russell, 1993; Cifelli et al., 1997; Zanno \& Makovicky 2011; Poropat et al., 2016). A direct Beringian connection has been invoked to explain apparent late Early Cretaceous dispersal events for tyrannosauroids (e.g., Zanno \& Makovicky 2011), therizinosaurians (e.g., Zanno 2010), and neoceratopsians (e.g., Farke et al. 2014), among other vertebrate groups (but see Brikiatis, 2016 for an alternative view). Uncertainty about the timing and duration of a late Early Cretaceous Bering land bridge and the importance of Europe as an intermediate between North America and Asia notwithstanding (Brikiatis, 2016), the balance of evidence suggests that a Beringian connection existed within a timeframe that could explain the arrival of brachiosaurids in East Asia from North America by the Albian/Cenomanian boundary.

A European origin for Asian brachiosaurids is also possible, and receives support from biogeographic and paleogeographic studies. Taxonomic surveys and empirical paleobiogeographic analyses indicate substantial faunal exchange between Europe and Asia in the Early Cretaceous (e.g., Russell, 1993; Upchurch et al. 2002; Chinnery-Allgeier \& Kirkland, 2010; Dunhill et al., 2016; Ding et al., 2020). Periodic establishment of a Russian Basin/Turgai marine barrier would have impeded terrestrial dispersal between Europe and Central Asia in the late Berriasian-early Hauterivian and early Albian, but otherwise connections between these landmasses are thought to have existed for much of the Early Cretaceous (Poropat et al. 2016 and references therein), providing potential routes for an ancestral population of European brachiosaurids to disperse into East Asia. This scenario is consistent with other fossil evidence that indicates commingling of Asian and European sauropod faunas in the Early Cretaceous. Isolated teeth from the Barremian of Spain bearing a distolingual boss - a feature that is otherwise known only in some East Asian sauropods, including the Berriasian-Hauterivian Euhelopus (Wiman, 1929; Wilson 2002; Barrett \& Wang, 2007; Suteethorn et al., 2013; Moore et al., 2020) - would seem to suggest that a subclade of euhelopodids spread across both Asia and Europe in the Early Cretaceous (Canudo et al., 2002). Recently, the discovery of an isolated anterior caudal vertebra of a rebbachisaurid in the Turonian Bissekty Formation of Uzbekistan, as well as possible rebbachisaurid teeth from the same formation, have been interpreted as evidence for dispersal of European rebbachisaurids into Central Asia sometime between the Barremian and Turonian (Averianov \& Sues, 2021). It should be noted, however, that the morphological basis for identifying the Bissekty Formation anterior caudal vertebra as a rebbachisaurid has been critically challenged by a reappraisal of the specimen by Lerzo et al. (2021), who rejected rebbachisaurid affinities and provided evidence in support of a

PeerJ reviewing PDF | (2021:04:60622:1:0:NEW 7 Jul 2021) 
736 titanosaurian identity, a hypothesis also previously favored by Sues et al. (2015) and Averianov

$737 \&$ Sues (2017). Regardless of the affinities of the Bissekty Formation specimen, the presence of

738 a brachiosaurid in the Longjing Formation can be explained by the existence of plausible

739 dispersal routes connecting East Asia to both Europe and North America during much of the

740 Early Cretaceous.

741 The second biogeographic scenario suggests that brachiosaurids and other major

742 neosauropod lineages were widely distributed across Pangaea, including East Asia, before the

743 separation of Laurasia from Gondwana in the latter half of the Middle Jurassic and the isolation

744 of East Asia from the rest of Laurasia from the Callovian-Tithonian (Poropat et al., 2016, Xu et

745 al., 2018, and references therein). In this scenario, the occurrence of YJDM 00008 in the middle

746 Cretaceous of northeast China reflects the persistence of brachiosaurids in Asia from the Middle

747 Jurassic through the Early Cretaceous. The heretofore unrecognized presence of brachiosaurids

748 in the region during this time would thus reflect biased sampling of the fossil record. Such a

749 scenario seems unlikely, given that substantial prospecting in Middle-Late Jurassic and Early

750 Cretaceous (particularly Barremian-Albian) strata of China has yielded a rich sauropod record

751 (118 collections containing sauropod specimens, according to the Fossilworks Database, April

$75215,2021)$ that, to date, appears to be wholly devoid of brachiosaurids. Nevertheless, the

753 possibility that sampling biases have obscured the presence of an early-arriving lineage of Asian

754 brachiosaurids should not be dismissed out of hand. Indeed, pervasive sampling artifacts may be

755 necessary to explain the apparent absence of undisputed neosauropods from the well-sampled,

756 sauropod-rich Middle-Late Jurassic horizons of the Junggar and Sichuan basins, given the recent

757 discovery of the dicraeosaurid Lingwulong in older strata of north central China (Xu et al., 2018).

758 Possible explanations for the scarcity of neosauropods (including brachiosaurids) in the Middle-

759 Late Jurassic and of brachiosaurids in the Early Cretaceous of Asia include low abundance or

760 diversity of these groups in their ecosystems, and failure to sample the preferred habitats in

761 which these groups were more abundant (Whitlock, 2011; Xu et al., 2018). These explanations

762 have been proposed to account for the relatively low occurrence of brachiosaurids in dinosaur-

763 bearing localities of the Morrison Formation (D'Emic \& Carrano, 2020). Thus, irrespective of

764 the series of events that might have brought a lineage of brachiosaurids to Asia, their extreme

765 rarity in currently sampled Early Cretaceous dinosaur-bearing horizons may reflect the concerted

766 effects of an overall low abundance and poor sampling of preferred habitats.

767

768

769

770

771

772

773

774

775

776

777

778

779

780

781

\section{Conclusions}

The recent discovery of a fossil-rich horizon near the base of the Albian-Cenomanian Longjing Formation has yielded numerous dinosaurian and other terrestrial vertebrate specimens, including an isolated maxilla of a neosauropod. Although fragmentary, this specimen preserves a striking morphology - axially twisted dentition - that is otherwise present only in brachiosaurids. Referral of YJDM 00008 to Brachiosauridae receives support from phylogenetic analysis under both equal and implied weights parsimony, providing the most convincing evidence to date that brachiosaurids dispersed into Asia at some point in their evolutionary history. Consideration of a possibly associated partial dentary (YJDM 00006) from the same site does not impact this conclusion. Several paleobiogeographic scenarios could account for the occurrence of a middle Cretaceous Asian brachiosaurid, including dispersal from either North America or Europe during the Early Cretaceous. These hypotheses can be tested by continued study of excavated specimens from the Longshan locality and future excavation in the Longjing Formation.

Peer) reviewing PDF | (2021:04:60622:1:0:NEW 7 Jul 2021) 
782

783

784

785

786

787

788

789

790

791

792

793

794

795

796

797

798

799

800

801

802

803

804

805

806

807

808

809

810

811

812

813

814

815

816

817

818

819

820

821

822

823

824

825

826

\section{Acknowledgements}

The authors would like to thank Ding Xiaoqing for preparing the specimen, James Tierney for his assistance in proofreading the manuscript, and Joey Stiegler and Ren Xinxin for discussion. Thoughtful comments by editor Andrew Farke and reviewers Philip Mannion and Verónica Díez-Díaz improved an earlier version of this manuscript. We are grateful to the Willi Hennig Society for sponsoring the free distribution of the TNT software.

\section{References}

Antunes, M.T., Mateus, O., 2003. Dinosaurs of Portugal. Comptes Rendus Palevol 2, 77-95.

Averianov, A., Ivantsov, S., Skutschas, P., Faingertz, A., Leshchinskiy. S., 2018. A new sauropod dinosaur from the Lower Cretaceous Ilek Formation, Western Siberia, Russia. Geobios 51:1-14. https://doi.org/10.1016/j.geobios.2017.12.004

Averianov, A., Sues, H.-D., 2017. Review of Cretaceous sauropod dinosaurs from Central Asia. Cretaceous Research 69, 184-197. https://doi.org/10.1016/j.cretres.2016.09.006

Averianov, A., Sues, H.-D., 2021. First rebbachisaurid sauropod dinosaur from Asia. PLoS ONE 16, e0246620. https://doi.org/10.1371/journal.pone.0246620

Barrett, P.M., Hasegawa, Y., Manabe, M., Isaji, S., Matsuoka, H., 2002. Sauropod dinosaurs from the Lower Cretaceous of eastern Asia: taxonomic and biogeographical implications. Palaeontology 45, 1197-1217. https://doi.org/10.1111/1475-4983.00282

Barrett, P.M., Wang, X.-L., 2007. Basal titanosauriform (Dinosauria, Sauropoda) teeth from the Lower Cretaceous Yixian Formation of Liaoning Province, China. Palaeoworld 16, 265271. https://doi.org/10.1016/j.palwor.2007.07.001

Berman, D.S., McIntosh, J.S., 1978. Skull and relationships of the Upper Jurassic sauropod Apatosaurus (Reptilia, Saurischia). Bulletin of the Carnegie Museum of Natural History $8,1-35$.

Bonaparte, J.F., 1986. The early radiation and phylogenetic relationships of the Jurassic sauropod dinosaurs, based on vertebral anatomy, in: Padian, K. (Ed.), The Beginning of the Age of Dinosaurs. Cambridge University Press, Cambridge, pp. 247-258.

Bonaparte, J.F., Coria, R.A., 1993. Un nuevo y gigantesco sauropodo titanosaurio de la Formacion Rio Limay (Albiano-Cenomaniano) de la Provincia del Neuquen, Argentina. Ameghiniana 30, 271-282.Bonaparte, J.F., González Riga, B.J., Apesteguía, S., 2006. Ligabuesaurus leanzai gen. et sp. nov. (Dinosauria, Sauropoda), a new titanosaur from the Lohan Cura Formation (Aptian, Lower Cretaceous) of Neuquén, Patagonia, Argentina. Cretaceous Research 27, 364-376.

https://doi.org/10.1016/j.cretres.2005.07.004

Brikiatis, L., 2016. Late Mesozoic North Atlantic land bridges. Earth-Science Reviews 159, 4757.

Buffetaut, E., Azar, D., Nel, A., Ziadé, K., Acra, A., 2006. First nonavian dinosaur from Lebanon: a brachiosaurid sauropod from the Lower Cretaceous of the Jezzine District. Naturwissenschaften 93, 440-443. https://doi.org/10.1007/s00114-006-0124-z

Calvo, J.O., Salgado, L., 1995. Rebbachisaurus tessonei sp. nov. a new sauropoda from the Albian-Cenomanian of Argentina; new evidence on the origin of the Diplodocidae. Gaia $11,13-33$.

Canudo, J.I., Ruiz-Omeñaca, J.I., Barco, J.L., Royo Torres, R., 2002. ¿Saurópodos asiáticos en el Barremiense inferior (Cretácico Inferior) de España? Ameghiniana 39, 443-452. 
827 Carballido, J.L., Pol, D., Otero, A., Cerda, I.A., Salgado, L., Garrido, A.C., Ramezani, J., Cúneo,

828

829

830

831

832

833

834

835

836

837

838

839

840

841

842

843

844

845

846

847

848

849

850

851

852

853

854

855

856

857

858

859

860

861

862

863

864

865

866

867

868

869

870

871

872
N.R., Krause, J.M., 2017. A new giant titanosaur sheds light on body mass evolution among sauropod dinosaurs. Proc. R. Soc. B. 284, 20171219. https://doi.org/10.1098/rspb.2017.1219

Carballido, J.L., Pol, D., Ruge, M.L.P., Bernal, S.P., Páramo-Fonseca, M.E., Etayo-Serna, F., 2015. A new Early Cretaceous brachiosaurid (Dinosauria, Neosauropoda) from northwestern Gondwana (Villa de Leiva, Colombia). Journal of Vertebrate Paleontology 35, e980505. https://doi.org/10.1080/02724634.2015.980505

Carballido, J.L., Sander, P.M., 2014. Postcranial axial skeleton of Europasaurus holgeri (Dinosauria, Sauropoda) from the Upper Jurassic of Germany: implications for sauropod ontogeny and phylogenetic relationships of basal Macronaria. Journal of Systematic Palaeontology 12, 335-387. https://doi.org/10.1080/14772019.2013.764935

Carballido, J.L., Scheil, M., Knötschke, N., Sander, P.M., 2020. The appendicular skeleton of the dwarf macronarian sauropod Europasaurus holgeri from the Late Jurassic of Germany and a re-evaluation of its systematic affinities. Journal of Systematic Palaeontology 18, 739-781. https://doi.org/10.1080/14772019.2019.1683770

Carpenter, Kenneth, Tidwell, V., 1998. Preliminary description of a $<\mathrm{i}>$ Brachiosaurus $<\mathrm{i} />$ skull from Felch Quarry 1, Garden Park, Colorado. Modern Geology 23, 69-84.

Chure, D., Britt, B.B., Whitlock, J.A., Wilson, J.A., 2010. First complete sauropod dinosaur skull from the Cretaceous of the Americas and the evolution of sauropod dentition. Naturwissenschaften 97, 379-391. https://doi.org/10.1007/s00114-010-0650-6

Cifelli, R.L., Kirkland, J.I., Weil, A., Deino, A.L., Kowallis, B.J., 1997. High-precision 40Ar39Ar geochronology and the advent of North America's Late Cretaceous terrestrial fauna. Proc. Natl. Acad. Sci. USA 5.

Coria, R.A., Chiappe, L.M., 2001. Tooth replacement in a sauropod premaxilla from the Upper Cretaceous of Patagonia, Argentina. Ameghiniana 38, 463-466.

Curry Rogers, K., Forster, C.A., 2004. The skull of Rapetosaurus krausei (Sauropoda: Titanosauria) from the Late Cretaceous of Madagascar. Journal of Vertebrate Paleontology 24, 121-144. https://doi.org/10.1671/A1109-10

Curry Rogers, K., Forster, C.A., 2001. The last of the dinosaur titans: a new sauropod from Madagascar. Nature 412, 530-534. https://doi.org/10.1038/35087566

D'Emic, M.D., 2012. The early evolution of titanosauriform sauropod dinosaurs. Zool J Linn Soc 166, 624-671. https://doi.org/10.1111/j.1096-3642.2012.00853.x

D'Emic, M. D., 2013. Revision of the sauropod dinosaurs of the Lower Cretaceous Trinity Group, southern USA, with the description of a new genus. Journal of Systematic Palaeontology 11(6):707-726. https://doi.org/10.1080/14772019.2012.667446

D’Emic, M.D., Carrano, M.T., 2020. Redescription of Brachiosaurid Sauropod Dinosaur Material From the Upper Jurassic Morrison Formation, Colorado, USA. Anat Rec 303, 732-758. https://doi.org/10.1002/ar.24198

D’Emic, M.D., Foreman, B.Z., Jud, N.A., 2016. Anatomy, systematics, paleoenvironment, growth, and age of the sauropod dinosaur Sonorasaurus thompsoni from the Cretaceous of Arizona, USA. Journal of Paleontology 90, 102-132. https://doi.org/10.1017/jpa.2015.67

D’Emic, M.D., Whitlock, J.A., Smith, K.M., Fisher, D.C., Wilson, J.A., 2013. Evolution of High Tooth Replacement Rates in Sauropod Dinosaurs. PLoS ONE 8, e69235. https://doi.org/10.1371/journal.pone.0069235 
873 D'Emic, M.D., Wilson, J.A., Thompson, R., 2010. The end of the sauropod dinosaur hiatus in

874

875

876

877

878

879

880

881

882

883

884

885

886

887

888

889

890

891

892

893

894

895

896

897

898

899

900

901

902

903

904

905

906

907

908

909

910

911

912

913

914

915

916

917

918 North America. Palaeogeography, Palaeoclimatology, Palaeoecology 297, 486-490. https://doi.org/10.1016/j.palaeo.2010.08.032

Ding, A., Pittman, M., Upchurch, P., O’Connor, J., Field, D.J., Xu, X., 2020. The Biogeography of Coelurosaurian Theropods and its Impact on their Evolutionary History (preprint). Paleontology. https://doi.org/10.1101/634170

Dong, Z., 1990. Sauropoda from the Kelameili Region of the Junggar Basin, Xinjiang Autonomous Region. Vertebrata Palasiatica 28, 43-58.

Dunhill, A.M., Bestwick, J., Narey, H., Sciberras, J., 2016. Dinosaur biogeographical structure and Mesozoic continental fragmentation: a network-based approach. J. Biogeogr. 43, 1691-1704. https://doi.org/10.1111/jbi.12766

Farke, A.A., Maxwell, W.D., Cifelli, R.L., Wedel, M.J., 2014. A Ceratopsian Dinosaur from the Lower Cretaceous of Western North America, and the Biogeography of Neoceratopsia. PLoS ONE 9, e112055. https://doi.org/10.1371/journal.pone.0112055

Filippi, L.S., Garrido, A.C., 2008. Pitekunsaurus macayai gen. et sp. nov., nuevo titanosaurio (Saurischia, Sauropoda) del Cretácico Superior de la Cuenca Neuquina, Argentina. Ameghiniana 45, 575-590.

Goloboff, P.A., 2014. Extended implied weighting. Cladistics 30, 260-272. https://doi.org/10.1111/cla.12047

Goloboff, P.A., 1993. Estimating Character Weights During Tree Search. Cladistics 9, 83-91. https://doi.org/10.1111/j.1096-0031.1993.tb00209.x

Goloboff, P.A., Catalano, S.A., 2016. TNT version 1.5, including a full implementation of phylogenetic morphometrics. Cladistics 32, 221-238. https://doi.org/10.1111/cla.12160

Goloboff, P.A., Torres, A., Arias, J.S., 2017. Weighted parsimony outperforms other methods of phylogenetic inference under models appropriate for morphology. Cladistics 34, 407-437.

https://doi.org/10.1111/cla.12205Holland, W. J. 1924. The skull of Diplodocus. Memoirs of the Carnegie Museum, 9, 379-403.

Ikejiri, T., Tidwell, V., Trexler, D.L., 2005. New adult specimens of Camarasaurus lentus highlight ontogenetic variation within the species, in: Thunder-Lizards: The Sauropodomorph Dinosaurs. Indiana University Press, Bloomington, pp. 154-179.

Janensch, W., 1935. Die Schädel der Sauropoden Brachiosaurus, Barosaurus und Dicraeosaurus aus den Tendaguru-schichten Deutsch-Ostafrikas. Palaeontographica 2, 145-298.

Janensch, W., 1914. Übersicht über die Wirbeltierfauna der Tendaguru-Schichten, nebst einer kurzen Charakterisierung der neu aufgeführten Arten von Sauropoden. Archiv Biontol 3, $81-110$.

Jin, D.C., Zhang, J.L., Xu, X., Jin, C.Z., Jin, F., Cai, Y.Y., 2018. A Preliminary Report on the Yanji Dinosaur Fauna in Jinlin. Acta Palaeontologica Sinica 57, 495-503.

Ksepka, D.T., Norell, M.A., 2010. The Illusory Evidence for Asian Brachiosauridae: New Material of Erketu ellisoni and a Phylogenetic Reappraisal of Basal Titanosauriformes. American Museum Novitates 3700, 1-27. https://doi.org/10.1206/3700.2

Kurzanov, S.M., Bannikov, A.F., 1983. A new sauropod from the Upper Cretaceous of Mongolia. Palaeontological Journal 2, 91-97.

Lapparent, A.F., 1943. Les dinosaures jurassiques de Damparis (Jura). Mémoires de la Société Géologique de France, Nouvelle Série 47, 1-21.

Lerzo, L. N., Carballido, J. L., Gallina, P. A., 2021. Rebbachisaurid sauropods in Asia? A reevaluation of the phylogenetic position of Dzharatitanis kingi from the Late Cretaceous

PeerJ reviewing PDF | (2021:04:60622:1:0:NEW 7 Jul 2021) 
919

920

921

922

923

924

925

926

927

928

929

930

931

932

933

934

935

936

937

938

939

940

941

942

943

944

945

946

947

948

949

950

951

952

953

954

955

956

957

958

959

960

961

962

963

964 of Uzbekistan. Publicación Electrónica de la Asociación Paleontológica Argentina 21(1):18-27. https://doi.org/10.5710//PEAPA.24.03.2021.389

Li, K., Liu, J., Yang, C., Hu, F., 2011. Dinosaur assemblages from the Middle Jurassic Shaximiao Formation and Chuanjie Formation in the Sichuan-Yunnan Basin, China. Volumina Jurassica 9, 21-42.

Li, L.-G., Li, D.-Q., You, H.-L., Dodson, P., 2014. A New Titanosaurian Sauropod from the Hekou Group (Lower Cretaceous) of the Lanzhou-Minhe Basin, Gansu Province, China. PLoS ONE 9, e85979. https://doi.org/10.1371/journal.pone.0085979

Lim, J.-D., Martin, L.D., Baek, K.-S., 2001. The first discovery of a brachiosaurid from the Asian continent. Naturwissenschaften 88, 82-84. https://doi.org/10.1007/s001140000201

Maddison, W.P., Maddison, D.R., 2019. Mesquite: a modular system for evolutionary analysis. http://www.mesquiteproject.org

Madsen, J.H., McIntosh, J.S., Berman, D.S., 1995. Skull and atlas-axis complex of the Upper Jurassic sauropod Camarasaurus Cope (Reptilia: Saurischia). Bulletin of the Carnegie Museum of Natural History 31, 1-115.

Mannion, P. D. 2011. A reassessment of Mongolosaurus haplodon Gilmore, 1933, a titanosaurian sauropod dinosaur from the Early Cretaceous of Inner Mongolia, People's Republic of China. Journal of Systematic Palaeontology 9: 355-378. https://doi.org/10.1080/14772019.2010.527379

Mannion, P.D., Allain, R., Moine, O., 2017. The earliest known titanosauriform sauropod dinosaur and the evolution of Brachiosauridae. PeerJ 5, e3217. https://doi.org/10.7717/peerj.3217

Mannion, P.D., Upchurch, P., Barnes, R.N., Mateus, O., 2013. Osteology of the Late Jurassic Portuguese sauropod dinosaur Lusotitan atalaiensis (Macronaria) and the evolutionary history of basal titanosauriforms. Zool J Linn Soc 168, 98-206. https://doi.org/10.1111/zoj.12029

Mannion, P.D., Upchurch, P., Jin, X., Zheng, W., 2019a. New information on the Cretaceous sauropod dinosaurs of Zhejiang Province, China: impact on Laurasian titanosauriform phylogeny and biogeography. Royal Society Open Science 6.

Mannion, P.D., Upchurch, P., Schwarz, D., Wings, O., 2019b. Taxonomic affinities of the putative titanosaurs from the Late Jurassic Tendaguru Formation of Tanzania: phylogenetic and biogeographic implications for eusauropod dinosaur evolution. Zoological Journal of the Linnean Society 126.

Marpmann, J.S., Carballido, J.L., Sander, P.M., Knötschke, N., 2015. Cranial anatomy of the Late Jurassic dwarf sauropod Europasaurus holgeri (Dinosauria, Camarasauromorpha): ontogenetic changes and size dimorphism. Journal of Systematic Palaeontology 13, 221263. https://doi.org/10.1080/14772019.2013.875074

Marsh, O.C., 1891. Restoration of $<\mathrm{i}>$ Triceratops $<\mathrm{i} />$. Restoration of $<\mathrm{i}>$ Brontosaurus $<\mathrm{i} />$. The American Journal of Science, 3 41, 339-342.

Marsh, O.C., 1884. Principal characters of American Jurassic dinosaurs. Part VII. On the Diplodocidae, a new family of the Sauropoda. American Journal of Science (Series 3) 27, 160-168.

Marsh, O.C., 1878. Principal characters of American Jurassic dinosaurs, Part I. American Journal of Science (Series 3) 16, 411-416.

Martínez, R.D.F., Lamanna, M.C., Novas, F.E., Ridgely, R.C., Casal, G.A., Martínez, J.E., Vita, J.R., Witmer, L.M., 2016. A Basal Lithostrotian Titanosaur (Dinosauria: Sauropoda) with

PeerJ reviewing PDF | (2021:04:60622:1:0:NEW 7 Jul 2021) 
965

966

967

968

969

970

971

972

973

974

975

976

977

978

979

980

981

982

983

984

985

986

987

988

989

990

991

992

993

994

995

996

997

998

999

1000

1001

1002

1003

1004

1005

1006

1007

1008

1009

1010 a Complete Skull: Implications for the Evolution and Paleobiology of Titanosauria. PLOS ONE 11, e0151661. https://doi.org/10.1371/journal.pone.0151661

Materialise, 2015. Mimics. Leuven, Belgium.

McPhee, B.W., Mannion, P.D., de Klerk, W.J., Choiniere, J.N., 2016. High diversity in the sauropod dinosaur fauna of the Lower Cretaceous Kirkwood Formation of South Africa: Implications for the Jurassic-Cretaceous transition. Cretaceous Research 59, 228-248. https://doi.org/10.1016/j.cretres.2015.11.006

Mo, J., 2013. Topics in Chinese Dinosaur Paleontology: Bellusaurus sui. Henan Science and Technology Press, Zhengzhou.

Mocho, P., Royo-Torres, R., Ortega, F., 2017. New data of the Portuguese brachiosaurid Lusotitan atalaiensis (Sobral Formation, Upper Jurassic). Historical Biology 29, 789817. https://doi.org/10.1080/08912963.2016.1247447

Moore, A.J., Mo, J., Clark, J.M., Xu, X., 2018. Cranial anatomy of Bellusaurus sui (Dinosauria: Eusauropoda) from the Middle-Late Jurassic Shishugou Formation of northwest China and a review of sauropod cranial ontogeny. PeerJ 6, e4881. https://doi.org/10.7717/peerj.4881

Moore, A.J., Upchurch, P., Barrett, P.M., Clark, J.M., Xing, X., 2020. Osteology of Klamelisaurus gobiensis (Dinosauria, Eusauropoda) and the evolutionary history of Middle-Late Jurassic Chinese sauropods. Journal of Systematic Palaeontology 18, 12991393. https://doi.org/10.1080/14772019.2020.1759706

Object Research Systems, Inc, 2021. Dragonfly. Montreal, Canada.

Ouyang, H., 1989. A new sauropod dinosaur from Dashanpu, Zigong County, Sichuan Province (Abrosaurus dongpoensis gen. et sp. nov.). Newsletter of the Zigong Dinosaur Museum 2, 10-14.

Owen, R., 1842. Report on British Fossil Reptiles, Part II. Report of the British Association for the Advancement of Science 11, 60-204.

Poropat, S.F., Kear, B.P., 2013. Photographic Atlas and Three-Dimensional Reconstruction of the Holotype Skull of Euhelopus zdanskyi with Description of Additional Cranial Elements. PLOS ONE 8, e79932. https://doi.org/10.1371/journal.pone.0079932

Poropat, S.F., Kundrát, M., Mannion, P.D., Upchurch, P., Tischler, T.R., Elliott, D.A., 2021. Second specimen of the Late Cretaceous Australian sauropod dinosaur Diamantinasaurus matildae provides new anatomical information on the skull and neck of early titanosaurs. Zoological Journal of the Linnean Society zlaa173. https://doi.org/10.1093/zoolinnean/zlaa173

Poropat, S.F., Mannion, P.D., Upchurch, P., Hocknull, S.A., Kear, B.P., Kundrát, M., Tischler, T.R., Sloan, T., Sinapius, G.H.K., Elliott, J.A., Elliott, D.A., 2016. New Australian sauropods shed light on Cretaceous dinosaur palaeobiogeography. Scientific Reports 6:34467. https://doi.org/10.1038/srep34467

Porter, W.R., Witmer, L.M., 2020. Vascular Patterns in the Heads of Dinosaurs: Evidence for Blood Vessels, Sites of Thermal Exchange, and Their Role in Physiological Thermoregulatory Strategies. Anat Rec 303, 1075-1103. https://doi.org/10.1002/ar.24234

Rauhut, O.W.M., 2006. A brachiosaurid sauropod from the Late Jurassic Cañadón Calcáreo Formation of Chubut, Argentina. Foss. Rec. 9, 226-237. https://doi.org/10.1002/mmng.200600010

Riggs, E.S., 1904. Structure and relationships of opisthocoelian dinosaurs. Part II, the Brachiosauridae. Field Columbian Museum, Geological Series 2 6, 229-247.

PeerJ reviewing PDF | (2021:04:60622:1:0:NEW 7 Jul 2021) 
1011 Riggs, E.S., 1903. Brachiosaurus altithorax, the largest known dinosaur. American Journal of

1012

1013

1014

1015

1016

1017

1018

1019

1020

1021

1022

1023

1024

1025

1026

1027

1028

1029

1030

1031

1032

1033

1034

1035

1036

1037

1038

1039

1040

1041

1042

1043

1044

1045

1046

1047

1048

1049

1050

1051

1052

1053

1054

1055 Science 15, 299-306.

Romer, A.S., 1956. Osteology of the Reptiles. University of Chicago Press, Chicago.

Rose, P.J., 2007. A new titanosauriform sauropod (Dinosauria: Saurischia) from the Early

Cretaceous of Central Texas and its phylogenetic relationships. Palaeontologia Electronica 10, 8A:65p.

Royo-Torres, R., Fuentes, C., Meijide, M., Meijide-Fuentes, F., Meijide-Fuentes, M., 2017. A new Brachiosauridae Sauropod dinosaur from the lower Cretaceous of Europe (Soria Province, Spain). Cretaceous Research 80, 38-55. https://doi.org/10.1016/j.cretres.2017.08.012

Russell, D.A., 1993. The role of Central Asia in dinosaurian biogeography. Canadian Journal of Earth Sciences 30, 2002-2012.

Saegusa, H., Tomida, Y., 2011. Titanosauriform teeth from the Cretaceous of Japan. An. Acad. Bras. Ciênc. 83, 247-265. https://doi.org/10.1590/S0001-37652011000100014

Salgado, L., Coria, R.A., Calvo, J.O., 1997. Evolution of titanosaurid sauropods. I: Phylogenetic analysis based on the postcranial evidence. Ameghiniana 34, 3-32.

Sander, P.M., Mateus, O., Laven, T., Knötschke, N., 2006. Bone histology indicates insular dwarfism in a new Late Jurassic sauropod dinosaur. Nature 441, 739-741. https://doi.org/10.1038/nature04633

Seeley, H., 1887. On the classification of the fossil animals commonly named Dinosauria. Proceedings of the Royal Society of London 43, 165-171.

Sereno, P.C., Wilson, J.A., Witmer, L.M., Whitlock, J.A., Maga, A., Ide, O., Rowe, T.A., 2007. Structural Extremes in a Cretaceous Dinosaur. PLOS ONE 2, e1230. https://doi.org/10.1371/journal.pone.0001230

Sues, H.-D., Averianov, A., Ridgely, R. C., Witmer. L. M., 2015. Titanosauria (Dinosauria, Sauropoda) from the Upper Cretaceous (Turonian) Bissekty Formation of Uzbekistan. Journal of Vertebrate Paleontology 35(1): e889145. https://doi.org/10.1080/02724634.2014.889145

Suteethorn, S., Loeuff, J.L., Buffetaut, E., Suteethorn, V., Talubmook, C., Chonglakmani, C., 2009. A new skeleton of Phuwiangosaurus sirindhornae (Dinosauria, Sauropoda) from NE Thailand. Geological Society of London. Journal contribution. https://doi.org/10.6084/m9.figshare.3454646.v1

Suteethorn, S., Loeuff, J.L., Buffetaut, E., Suteethorn, V., Wongko, K., 2013. First Evidence of a Mamenchisaurid Dinosaur from the Upper Jurassic-Lower Cretaceous Phu Kradung Formation of Thailand. Acta Palaeontologica Polonica 58, 459-469. https://doi.org/10.4202/app.2009.0155

Taylor, M.P., Naish, D., 2005. The phylogenetic taxonomy of Diplodocoidea (Dinosauria: Sauropoda). PaleoBios 25, 1-7.

Torcida Fernández-Baldor, F., Canudo, J.I., Huerta, P., Moreno-Azanza, M., Montero, D., 2017. Europatitan eastwoodi, a new sauropod from the lower Cretaceous of Iberia in the initial radiation of somphospondylans in Laurasia. PeerJ 5: e3409. http://doi.org/10.7717/peerj.3409

Tschopp, E., Mateus, O., 2017. Osteology of Galeamopus pabsti sp. nov. (Sauropoda: Diplodocidae), with implications for neurocentral closure timing, and the cervico-dorsal transition in diplodocids. PeerJ 5, e3179. https://doi.org/10.7717/peerj.3179 
1056 Tschopp, E., Mateus, O., 2013. The skull and neck of a new flagellicaudatan sauropod from the

1057

1058

1059

1060

1061

1062

1063

1064

1065

1066

1067

1068

1069

1070

1071

1072

1073

1074

1075

1076

1077

1078

1079

1080

1081

1082

1083

1084

1085

1086

1087

1088

1089

1090

1091

1092

1093

1094

1095

1096

1097

1098

1099

1100
Morrison Formation and its implication for the evolution and ontogeny of diplodocid dinosaurs. Journal of Systematic Palaeontology 11, 853-888. https://doi.org/10.1080/14772019.2012.746589

Tschopp, E., Mateus, O., Benson, R.B.J., 2015. A specimen-level phylogenetic analysis and taxonomic revision of Diplodocidae (Dinosauria, Sauropoda). PeerJ 3, e857. https://doi.org/10.7717/peerj.857

Upchurch, P., Barrett, P.M., Dodson, P., 2004. Sauropoda, in: Dodson, Peter, Osmólska, H., Weishampel, D. (Eds.), The Dinosauria: Second Edition. pp. 259-322.

Upchurch, P., Hunn, C.A., Norman, D.B., 2002. An analysis of dinosaurian biogeography: evidence for the existence of vicariance and dispersal patterns caused by geological events. Proc. R. Soc. Lond. B 269, 613-621. https://doi.org/10.1098/rspb.2001.1921

Upchurch, P., Mannion, P.D., 2009. The first diplodocid from Asia and its implications for the evolutionary history of sauropod dinosaurs. Palaeontology 52, 1195-1207. https://doi.org/10.1111/j.1475-4983.2009.00909.x

Wang, Y.F., Cun-Feng, W., Jie-Min, Q., Zhang, W.D., Cui-Li, S., Yan-Feng, S., 2019. Development and applications of paleontological computed tomography. Vertebrata Palasiatica 51, 84-92. https://doi.org/10.19615/j.cnki.1000-3118.170921

White, T.E., 1958. The braincase of Camarasaurus lentus (Marsh). Journal of Paleontology 32 , 477-494.

Whitlock, J.A., 2011a. A phylogenetic analysis of Diplodocoidea (Saurischia: Sauropoda). Zool J Linn Soc 161, 872-915. https://doi.org/10.1111/j.1096-3642.2010.00665.x

Whitlock, J.A., 2011b. Inferences of Diplodocoid (Sauropoda: Dinosauria) Feeding Behavior from Snout Shape and Microwear Analyses. PLOS ONE 6, e18304. https://doi.org/10.1371/journal.pone.0018304

Whitlock, J.A., D’Emic, M.D., Wilson, J.A., 2011. Cretaceous diplodocids in Asia? Reevaluating the phylogenetic affinities of a fragmentary specimen. Palaeontology 54, 351364. https://doi.org/10.1111/j.1475-4983.2010.01029.x

Wilson, J., 2002. Sauropod dinosaur phylogeny: critique and cladistic analysis. Zoological Journal of the Linnean Society 136, 215-275. https://doi.org/10.1046/j.1096$\underline{3642.2002 .00029 . x}$

Wilson, J.A., 2005. Redescription of the Mongolian sauropod Nemegtosaurus mongoliensis Nowinski (Dinosauria: Saurischia) and comments on Late Cretaceous sauropod diversity. Journal of Systematic Palaeontology 3, 283-318. https://doi.org/10.1017/S1477201905001628

Wilson, J.A., Pol, D., Carvalho, A.B., Zaher, H., 2016. The skull of the titanosaur Tapuiasaurus macedoi (Dinosauria: Sauropoda), a basal titanosaur from the Lower Cretaceous of Brazil. Zool J Linn Soc 178, 611-662. https://doi.org/10.1111/zoj.12420

Wilson, J.A., Sereno, P.C., 1998. Early Evolution and Higher-Level Phylogeny of Sauropod Dinosaurs. Journal of Vertebrate Paleontology 18, 1-79. https://doi.org/10.1080/02724634.1998.10011115

Wilson, J.A., Upchurch, P., 2009. Redescription and reassessment of the phylogenetic affinities of Euhelopus zdanskyi (Dinosauria: Sauropoda) from the Early Cretaceous of China. Journal of Systematic Palaeontology 7, 199-239. https://doi.org/10.1017/S1477201908002691

PeerJ reviewing PDF | (2021:04:60622:1:0:NEW 7 Jul 2021) 
1101 Wilson, J.A., Upchurch, P., 2003. A revision of Titanosaurus Lydekker (Dinosauria -

1102

1103

1104

1105

1106

1107

1108

1109

1110

1111

1112

1113

1114

1115

1116

1117

1118

1119

1120

1121

1122

1123

1124

1125

1126

1127

1128

1129

1130
Sauropoda), the first dinosaur genus with a 'Gondwanan' distribution. Journal of Systematic Palaeontology 1, 125-160. https://doi.org/10.1017/S1477201903001044

Wiman, C., 1929. Die Kreide-Dinosaurier aus Shantung. Palaeontologia Sinica (series C) 6, $1-$ 67.

Xu, X., Upchurch, P., Mannion, P.D., Barrett, P.M., Regalado-Fernandez, O.R., Mo, J., Ma, J., Liu, H., 2018. A new Middle Jurassic diplodocoid suggests an earlier dispersal and diversification of sauropod dinosaurs. Nature Communications 9. https://doi.org/10.1038/s41467-018-05128-1

Ye, Y., Gao, Y.-H., Jiang, S., 2005. A new genus of sauropod from Zigong, Sichuan. Vertebrata Palasiatica 43, 175-181.

You, H.-L., Li, D.-Q., 2009. The first well-preserved Early Cretaceous brachiosaurid dinosaur in Asia. Proceedings of the Royal Society of London B: Biological Sciences 276, 40774082. https://doi.org/10.1098/rspb.2009.1278

You, H., Morschhauser, E.M., Li, D., Dodson, P., 2018. Introducing the Mazongshan Dinosaur Fauna. Journal of Vertebrate Paleontology 38, 1-11. https://doi.org/10.1080/02724634.2017.1396995

Zaher, H., Pol, D., Carvalho, A.B., Nascimento, P.M., Riccomini, C., Larson, P., Juarez-Valieri, R., Pires-Domingues, R., Jr, N.J. da S., Campos, D. de A., 2011. A Complete Skull of an Early Cretaceous Sauropod and the Evolution of Advanced Titanosaurians. PLOS ONE 6, e16663. https://doi.org/10.1371/journal.pone.0016663

Zanno, L.E., Makovicky, P.J., 2011. On the earliest record of Cretaceous tyrannosauroids in western North America: implications for an Early Cretaceous Laurasian interchange event. Historical Biology 23, 317-325. https://doi.org/10.1080/08912963.2010.543952

Zhang, L.Z., Jin, C.Z., Yin, Q.Z., Hyskens, M., Jin, D.C., Zhang J L, Xu, X., 2018. A new dinosaur fossil locality of Mid-Creataceous age in northeastern China. Abstract of Papers, Society of Vertebrate Paleontology (October 2018), 78th Annual Meeting 236.

Zhong, Y., Wang, Y., Jia, B., Wang, M., Hu, L., Pan, Y., 2021. A potential terrestrial AlbianCenomanian boundary in the Yanji Basin, Northeast China. Palaeogeography, Palaeoclimatology, Palaeoecology 562, 11 
Table $\mathbf{1}$ (on next page)

Phylogenetic definitions 


\begin{tabular}{|l|l|l|}
\hline $\begin{array}{l}\text { Clade name / } \\
\text { author }\end{array}$ & Definition & Reference \\
\hline $\begin{array}{l}\text { Neosauropoda } \\
\text { Bonaparte (1986) }\end{array}$ & $\begin{array}{l}\text { The least inclusive clade containing Saltasaurus } \\
\text { loricatus and Diplodocus longus }\end{array}$ & Wilson \& Sereno (1998) \\
\hline $\begin{array}{l}\text { Diplodocoidea } \\
\text { Marsh (1884) }\end{array}$ & $\begin{array}{l}\text { The most inclusive clade that includes Diplodocus } \\
\text { longus but excludes Saltasaurus loricatus }\end{array}$ & Wilson \& Sereno (1998) \\
\hline $\begin{array}{l}\text { Diplodocimorpha } \\
\text { Calvo \& Salgado } \\
\text { (1995) }\end{array}$ & $\begin{array}{l}\text { Diplodocus, Rebbachisaurus, their most recent } \\
\text { common ancestor, and all of its descendents }\end{array}$ & Taylor \& Naish (2005) \\
\hline $\begin{array}{l}\text { Macronaria } \\
\text { Wilson \& Sereno } \\
(1998)\end{array}$ & $\begin{array}{l}\text { The most inclusive clade that includes Saltasaurus } \\
\text { loricatus but excludes Diplodocus longus }\end{array}$ & Wilson \& Sereno (1998) \\
\hline $\begin{array}{l}\text { Titanosauriformes } \\
\text { Salgado et al. } \\
(1997)\end{array}$ & $\begin{array}{l}\text { The least inclusive clade including Brachiosaurus } \\
\text { altithorax and Saltasaurus loricatus }\end{array}$ & Salgado et al. (1997) \\
\hline $\begin{array}{l}\text { Brachiosauridae } \\
\text { Riggs (1904) }\end{array}$ & $\begin{array}{l}\text { The most inclusive clade that includes } \\
\text { Brachiosaurus altithorax but excludes Saltasaurus } \\
\text { loricatus }\end{array}$ & Wilson \& Sereno (1998) \\
\hline $\begin{array}{l}\text { Somphospondyli } \\
\text { Wilson \& Sereno } \\
(1998)\end{array}$ & $\begin{array}{l}\text { The most inclusive clade that includes Saltasaurus } \\
\text { loricatus but excludes Brachiosaurus altithorax }\end{array}$ & Wilson \& Sereno (1998); \\
\hline $\begin{array}{l}\text { Euhelopodidae } \\
\text { Romer (1956) }\end{array}$ & $\begin{array}{l}\text { The most inclusive clade that includes Euhelopus } \\
\text { zdanskyi but excludes Neuquensaurus australis }\end{array}$ & D'Emic (2004) \\
\hline $\begin{array}{l}\text { Titanosauria } \\
\text { Bonaparte \& } \\
\text { Coria (1993) }\end{array}$ & $\begin{array}{l}\text { The least inclusive clade that includes Andesaurus } \\
\text { delgadoi and Saltasaurus loricatus }\end{array}$ & Wilson \& Upchurch (2003) \\
\hline $\begin{array}{l}\text { Lithostrotia } \\
\text { Wilson \& } \\
\text { Upchurch (2003) }\end{array}$ & $\begin{array}{l}\text { The least inclusive clade containing Malawisaurus } \\
\text { dixeyi and Saltasaurus loricatus }\end{array}$ & Wilson \& Upchurch (2003); \\
\hline
\end{tabular}




\section{Table 2 (on next page)}

Replacement teeth measurements.

All measurements were taken digitally in Dragonfly v.2021.1.0.977 on the oldest generation of replacement tooth within a given alveolus. Because it was not possible to observe textural differences of the enamel that distinguish the root from the crown, measurements of apicobasal crown length are necessarily approximations that may slightly overestimate this length. Rt, replacement tooth of a given alveolus. 
1

\begin{tabular}{|l|l|l|l|l|l|l|l|}
\hline & Rt2 & Rt3 & Rt4 & Rt5 & Rt6 & Rt7 & Rt10 \\
\hline $\begin{array}{l}\text { Apicobasal crown } \\
\text { length (mm) }\end{array}$ & 28.83 & 23.55 & 28.30 & 24.63 & 30.44 & 24.98 & 20.10 \\
\hline Crown width (mm) & 10.81 & 10.23 & 10.74 & 9.31 & 8.55 & 9.51 & 8.43 \\
\hline SI & 2.67 & 2.30 & 2.64 & 2.65 & 3.56 & 2.63 & 2.38 \\
\hline $\begin{array}{l}\text { Twist angle } \\
\text { (degrees) }\end{array}$ & 56 & 58 & 55 & 45 & 40 & 29 & 55 \\
\hline
\end{tabular}

2 
Figure 1

Map showing the locality of YJDM 00008 \& YJDM 00006 (red flag) in Jilin Province, China.

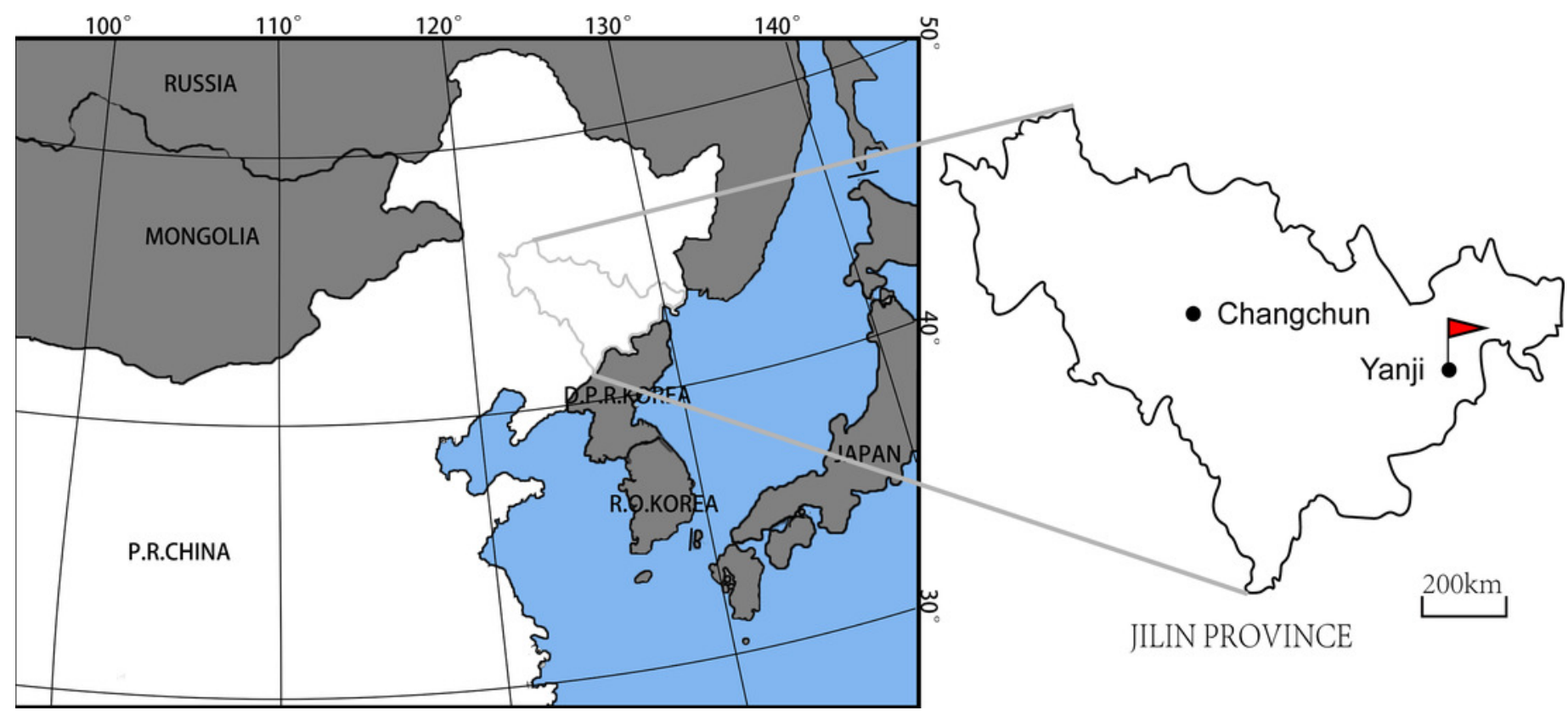


Figure 2

(A) Photograph and (B) line drawing of YJDM 00008 in lateral view.

Abbreviation: amf, anterior maxillary foramen; amp, anteromedial process; $\mathbf{n f}$, narial

fossa; jp, jugal process; sf, subnarial foramen; nvg, neurovascular groove. Scale bar equals $5 \mathrm{~cm}$. 

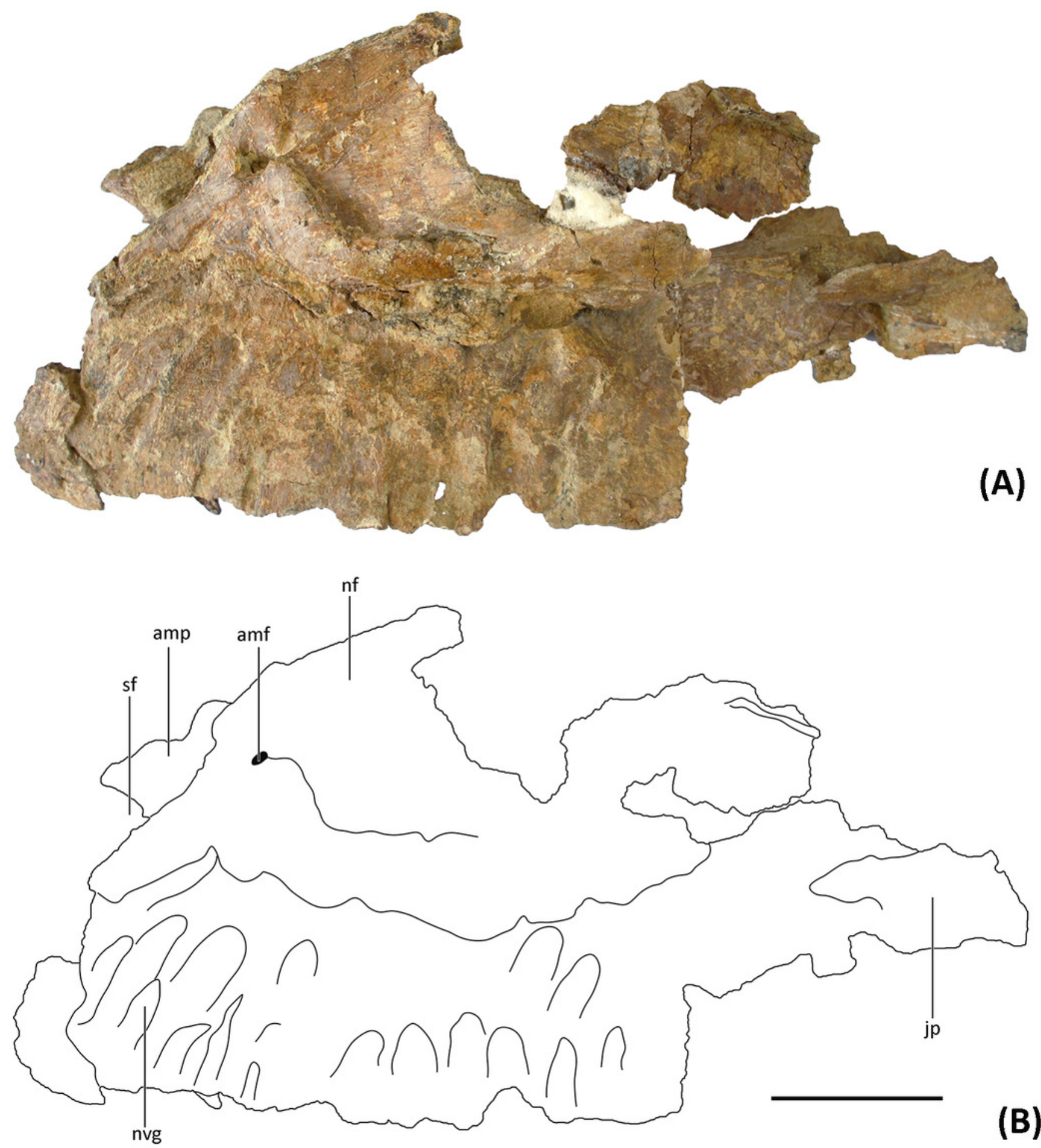
Figure 3

(A) Photograph and (B) line drawing of YJDM 00008 in medial view.

Abbreviation: amp, anteromedial process; ?a.pal, ?articular surface for the palatine;

g.pm, groove for articulation with the premaxilla ; inaof, internal antorbital fossa; jp, jugal process; rf, replacement foramen ; rt, replacement teeth; sf, subnarial foramen. Scale bar equals $5 \mathrm{~cm}$. 

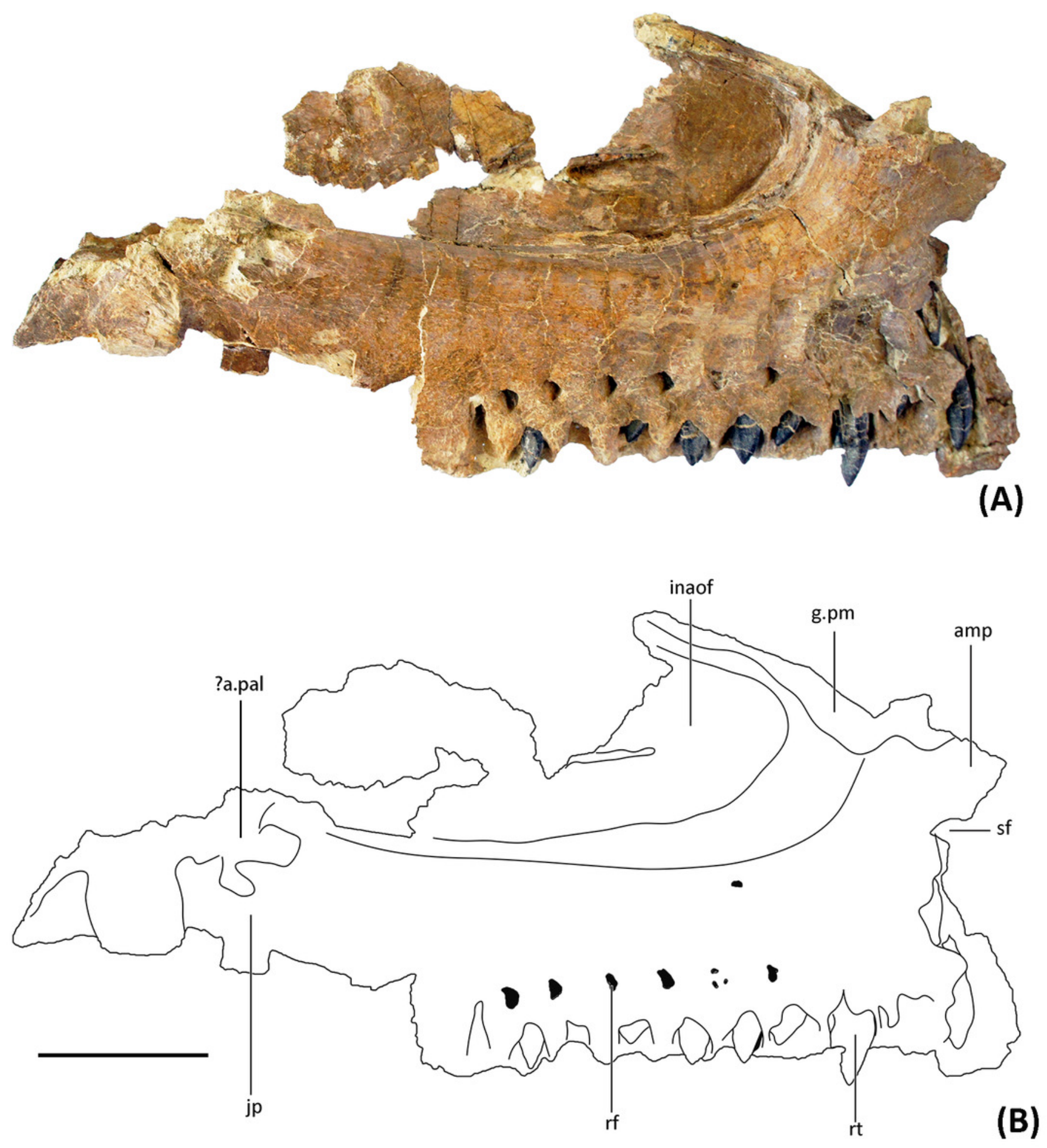
Figure 4

Photograph and line drawing of YJDM 00008 in ventral view (A), (C) and in anterolateral view (B), (D).

Abbreviation: amp, anteromedial process; $\mathbf{g . p m}$, groove for articulation with the premaxilla; inaof, internal antorbital fossa; jp, jugal process; nf, narial fossa; nvg, neurovascular groove; rf, replacement foramen; rt, replacement teeth; sf, subnarial foramen. Scale bars equal $5 \mathrm{~cm}$.

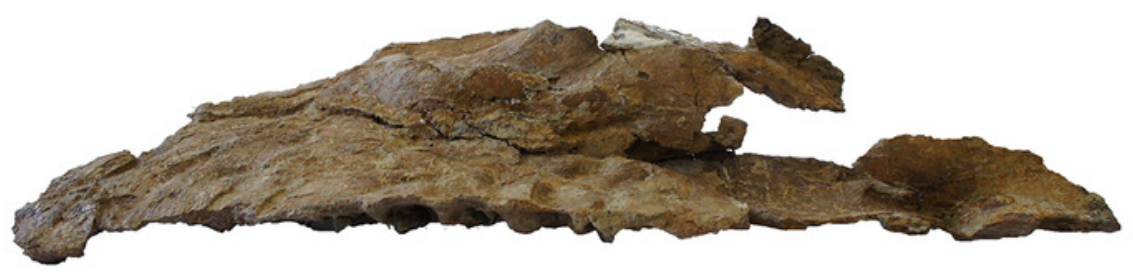

(A)
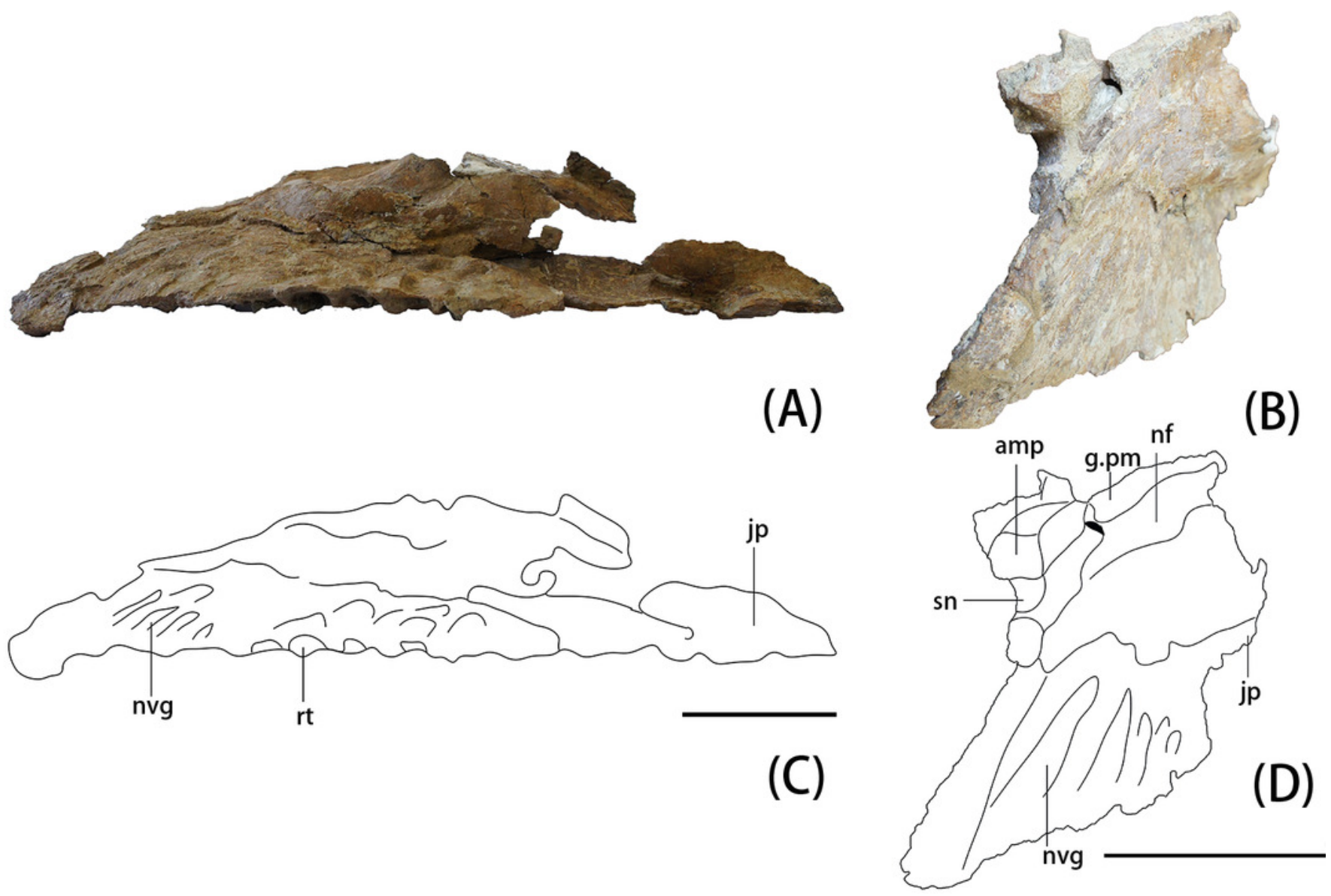
Figure 5

Photograph and CT slices of the dentition of YJDM 00008 in lingual view $(A, B)$, posterior view $(C)$, and ventral view (D).

The red arrows indicate the second generation of replacement teeth. Scale bar for (A) equals $3 \mathrm{~cm}$. 

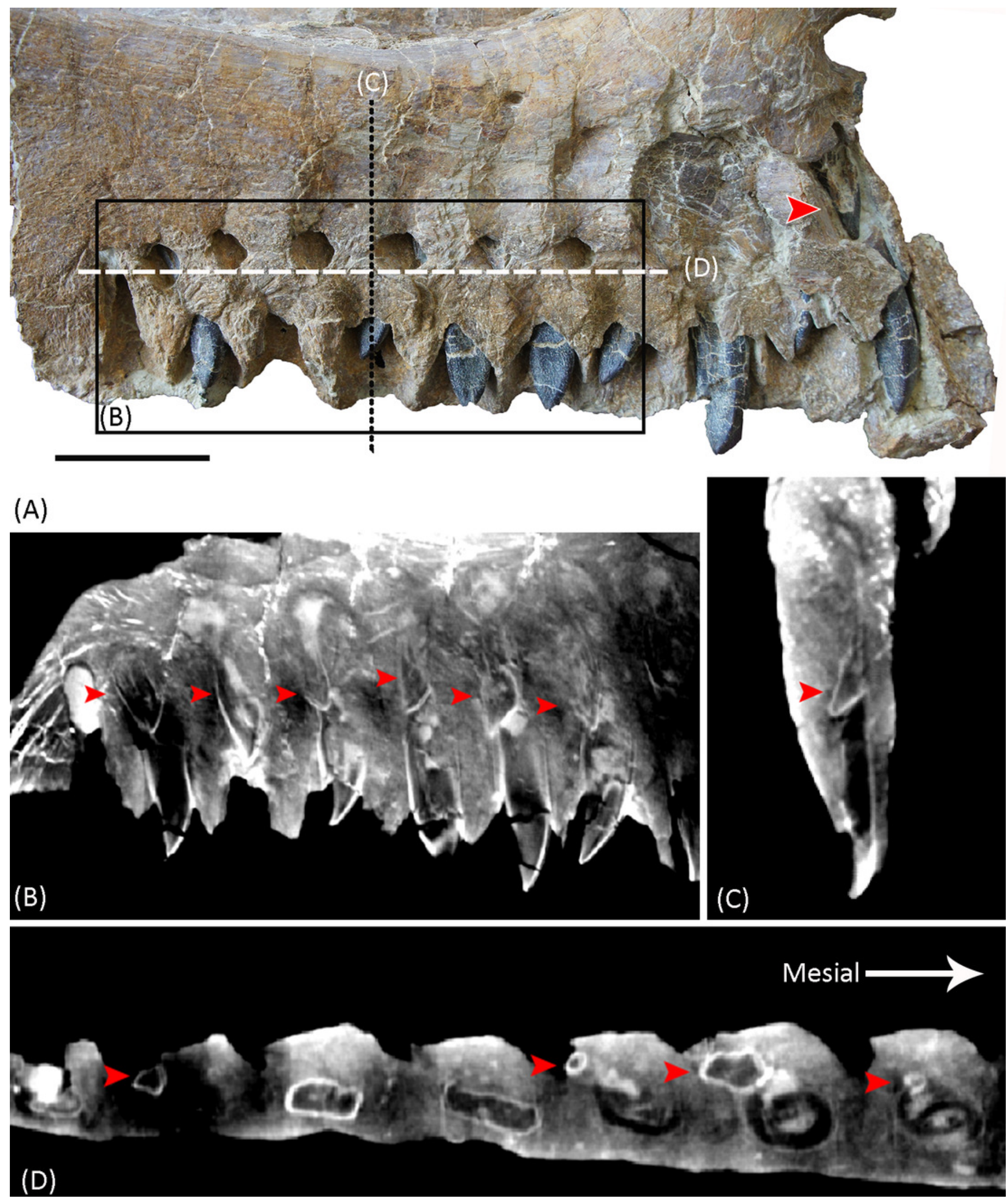
Figure 6

Successive CT slices demonstrating that the mesiodistal axis of the maxillary teeth (yellow bars) of YJDM 00008 are twisted longitudinally.

The pictures from top to bottom are cross-sections from dorsal to ventral. 


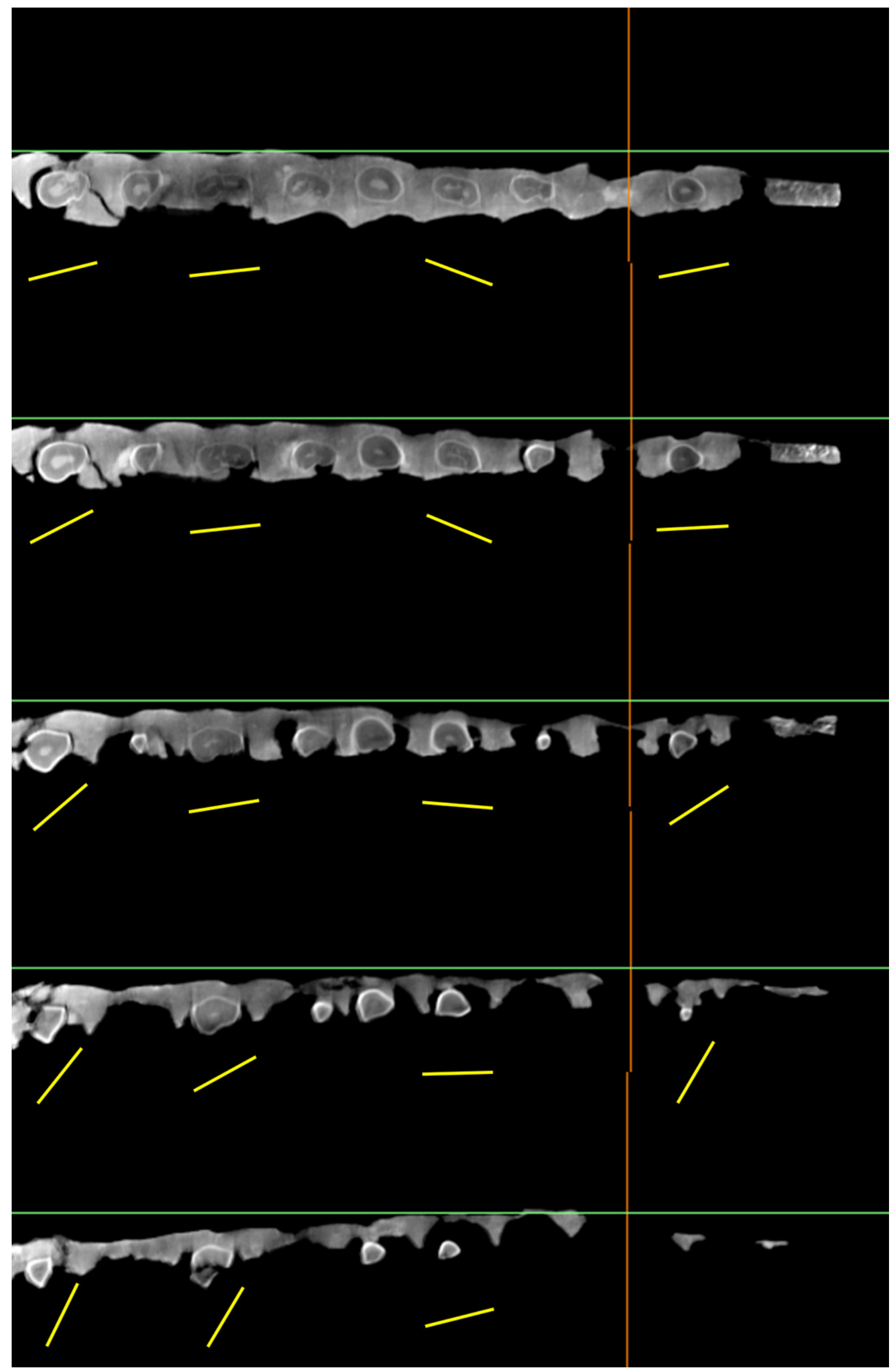

PeerJ reviewing PDF | (2021:04:60622:1:0:NEW 7 Jul 2021) 
Figure 7

Photographs of YJDM 00006 in lateral view (A), medial view (B), and dorsomedial view (C).

Abbreviation: pdp, posterodorsal process; pvp, posteroventral process; rt, replacement teeth. Scale bar for (A, B) equals $5 \mathrm{~cm}$, and for $(C)$ equals $2 \mathrm{~cm}$. 


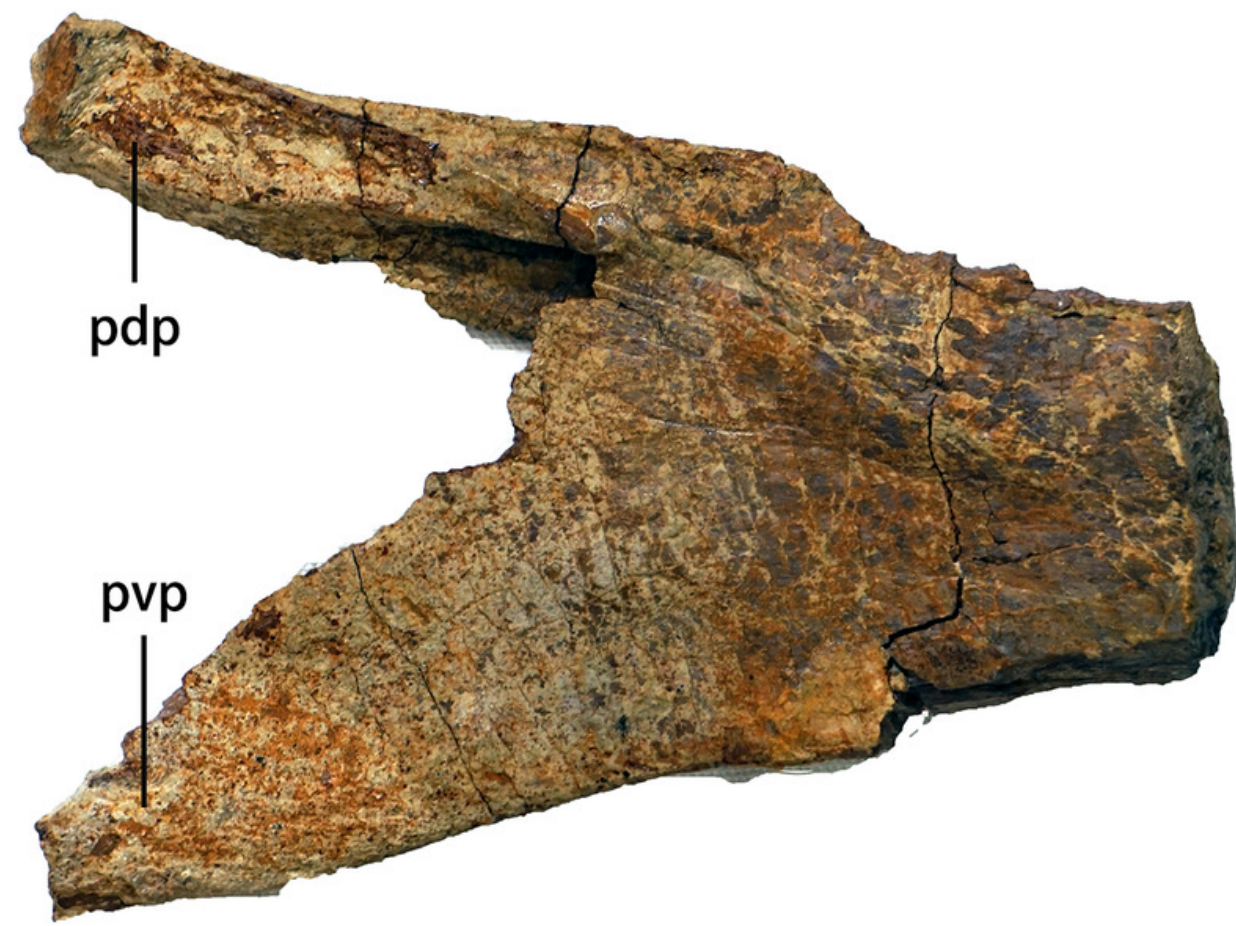

(A)

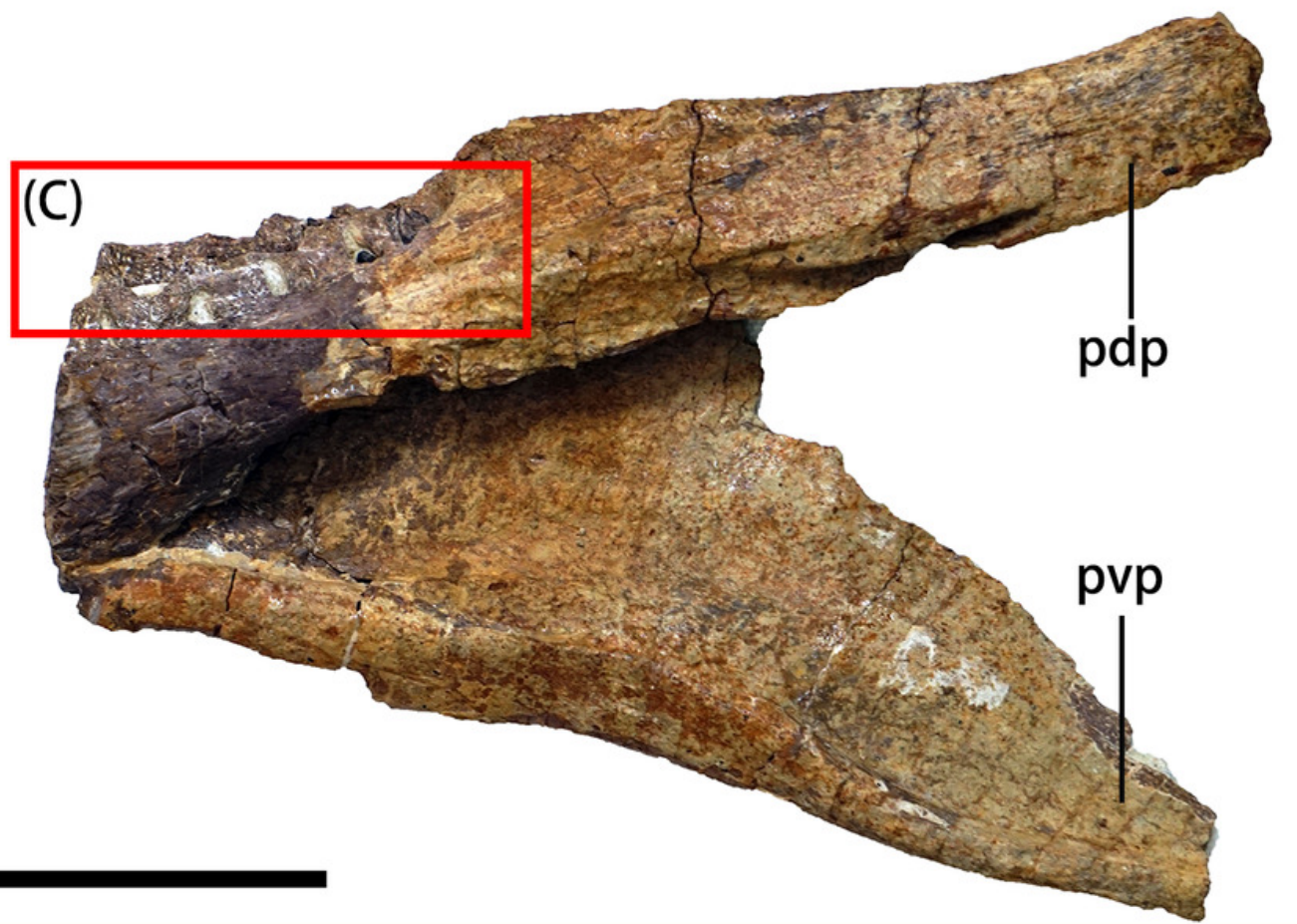

(B)

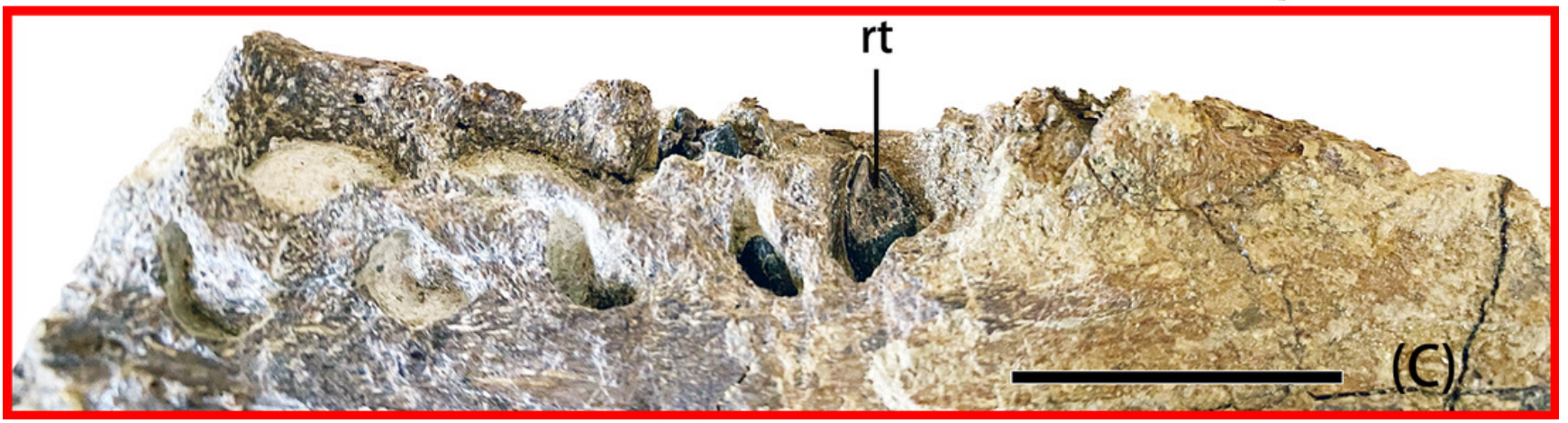

PeerJ reviewing PDF | (2021:04:60622:1:0:NEW 7 Jul 2021) 
Figure 8

Strict consensus topology resulting from the maxilla-only phylogenetic analysis under equal weights parsimony.

Red dashed lines indicate equally parsimonious positions for YJDM 00008. 


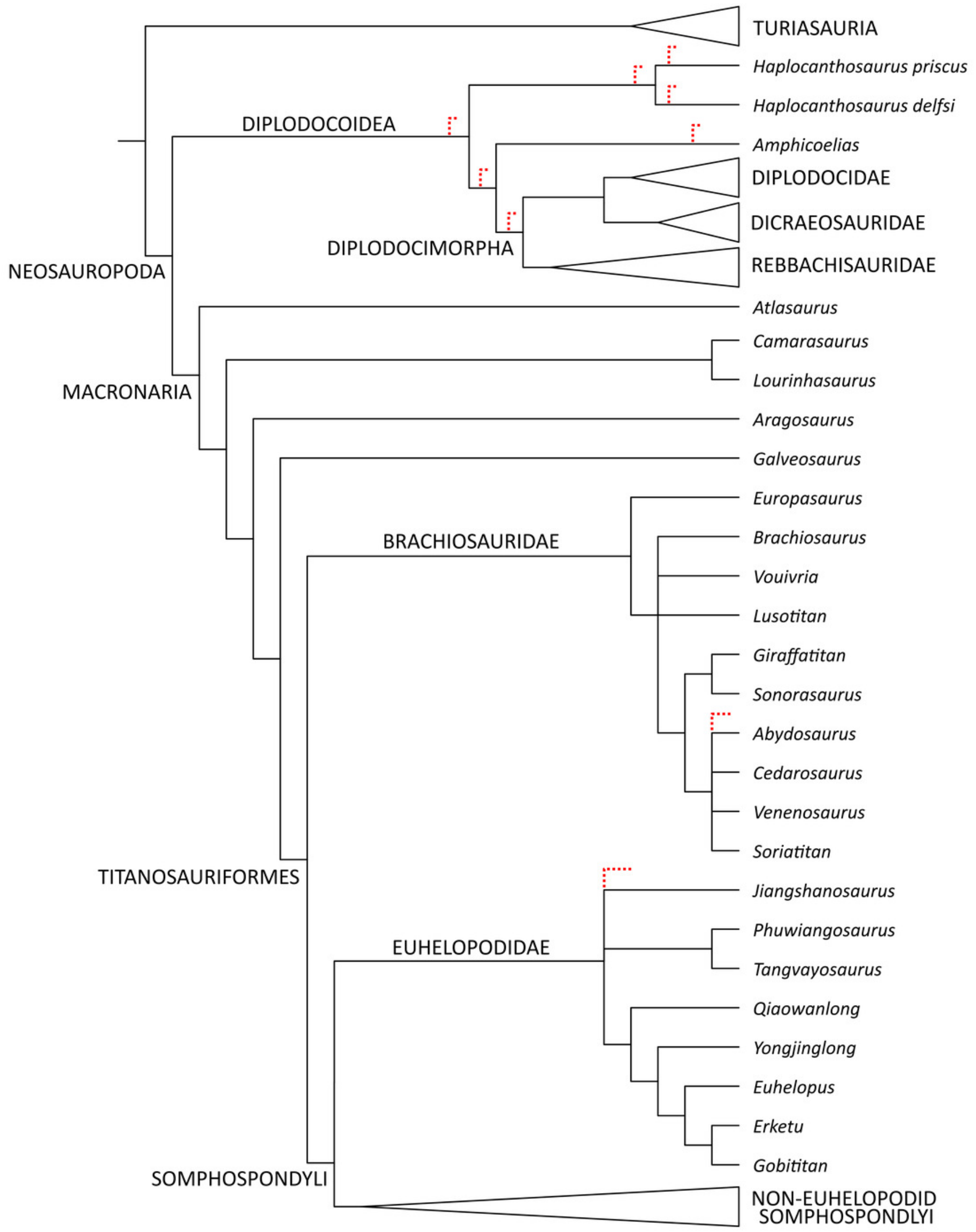




\section{Figure 9}

Time-calibrated strict consensus tree resulting from the maxilla-only extended implied weights analysis demonstrating the relationships among neosauropods and the phylogenetic position of YJDM 00008.

Time-calibrated strict consensus tree resulting from the maxilla-only extended implied weights analysis demonstrating the relationships among neosauropods and the phylogenetic position of YJDM 00008.

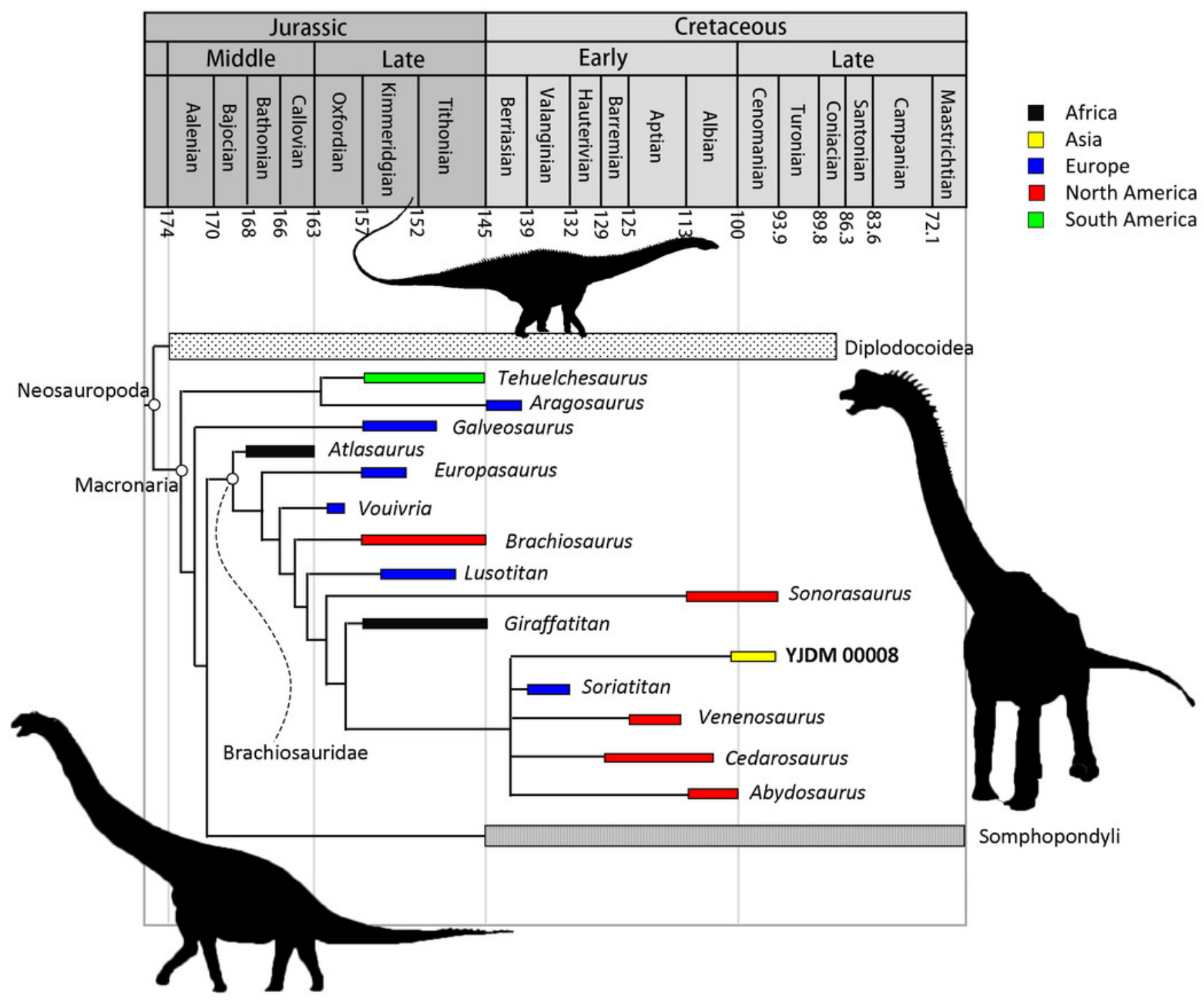

